\title{
Article \\ Electric-Potential-Assisted Crystallisation of L-Isoleucine: A Study of Nucleation Kinetics and Its Associated Parameters
}

\author{
Nik Salwani Md Azmi ${ }^{1}$, Nornizar Anuar ${ }^{1, *(D)}$, Muhamad Fitri Othman ${ }^{1}\left(\mathbb{D}\right.$, Noor Fitrah Abu Bakar ${ }^{1}$ \\ and Mohd Nazli Naim ${ }^{2}$ (D) \\ 1 School of Chemical Engineering, College of Engineering, Universiti Teknologi MARA, \\ Shah Alam 40450, Selangor, Malaysia; niksalwanimdazmi@gmail.com (N.S.M.A.); \\ fitri@uitm.edu.my (M.F.O.); fitrah@uitm.edu.my (N.F.A.B.) \\ 2 Department of Process and Food Engineering, Faculty of Engineering, Universiti Putra Malaysia, \\ Serdang 43400, Selangor, Malaysia; mohdnazli@upm.edu.my \\ * Correspondence: nornizar@uitm.edu.my
}

check for updates

Citation: Azmi, N.S.M.; Anuar, N.; Othman, M.F.; Bakar, N.F.A.; Naim, M.N. Electric-Potential-Assisted Crystallisation of L-Isoleucine: A Study of Nucleation Kinetics and Its Associated Parameters. Crystals 2021, 11, 620. https://doi.org/ $10.3390 /$ cryst11060620

Academic Editors: Elena Simone and Ian Rosbottom

Received: 26 January 2021

Accepted: 10 May 2021

Published: 31 May 2021

Publisher's Note: MDPI stays neutral with regard to jurisdictional claims in published maps and institutional affiliations.

Copyright: (c) 2021 by the authors. Licensee MDPI, Basel, Switzerland. This article is an open access article distributed under the terms and conditions of the Creative Commons Attribution (CC BY) license (https:// creativecommons.org/licenses/by/ $4.0 /)$.

\begin{abstract}
The potential of producing L-isoleucine crystals with the aid of electric potential and its effect on the nucleation kinetics of L-isoleucine were probed using polythermal and isothermal crystallisation techniques, assisted with $5 \mathrm{~V}, 9 \mathrm{~V}$, and $20 \mathrm{~V}$ electric potentials. The polythermal experiments were conducted with cooling rates of $0.1^{\circ} \mathrm{C} / \mathrm{min}-0.7^{\circ} \mathrm{C} / \mathrm{min}$, whilst isothermal crystallisation was conducted with a supersaturation of 1.30-1.70, and both were carried out in a $200 \mathrm{~mL}$ temperature-controlled jacketed reactor. Prediction of the nucleation rate and its associated parameters for isothermal crystallisation was carried out using a molecular dynamics simulation. In both crystallisation techniques, electric potentials increased the nucleation rate, but the intensity of the electric potential had less impact on the measured parameters. Nucleation rates for $5 \mathrm{~V}$ isothermal crystallisation were in the order of $10^{10}$ higher than for polythermal crystallisation. Electric potential doubled the nucleation rates for polythermal crystallisation and increased the nucleation rates 12-fold in isothermal crystallisation. The isothermal technique produced the form B polymorph, but mixtures of forms A and B were produced in polythermal crystallisation. The predicted critical number of molecules, $\mathrm{N}^{*}$, and the critical radius, $\mathrm{r}^{*}$, were in good agreement with the experimental data, with a higher predicted nucleation rate in the order of $10^{2}$.
\end{abstract}

Keywords: molecular dynamics simulation; metastable zone width (MSZW); nucleation rate; polythermal and isothermal crystallisation; homogeneous and heterogeneous nucleation; nucleation kinetics; critical radius; electrocrystallisation

\section{Introduction}

It is a well-known fact that controlling the nucleation rate and growth of a crystal to obtain desired crystals during crystallisation is a problem, particularly for pharmaceutical development and manufacturing. The proper design and control of the nucleation process are important to obtain the correct properties of the drugs, such as the polymorphic forms and morphology [1,2]. Recent advancements have probed the use of digital information and design to predict and improve the physical properties and performance of drug manufacturing [3]. Among the challenges is the control of nucleation to improve the physico-chemical properties, quality, and yield of crystals. Traditionally, nucleation can be controlled through the manipulation of crystallisation variables, such as supersaturation [4,5], stirring rates [6] and cooling rates [7], depending on the crystallisation technique adopted. In the case of the polythermal crystallisation technique, nucleation can be induced by reducing the width of the kinetically inactive metastable zone region by applying external influences, such as seeding [8], the addition of additives [4,9] and solvents (termed antisolvent) [10], a magnetic field [11], ultrasonic radiation [12] and electric potential [13-15]. However, 
manipulation of the region width could be at the expense of crystal quality produced, such as the polymorphic form, crystal shape and crystallinity [16].

Numerous studies of the application of an electric field in crystallisation with a wide range of electric potential intensity, for example, $2.4 \mathrm{~V} / \mathrm{cm}$ [17], $860 \mathrm{~V} / \mathrm{cm}[18]$ and $1 \times 10^{6}$ to $1 \times 10^{8} \mathrm{~V} / \mathrm{cm}$ [19], have been reported. From their work, it was concluded that an electric field increases the ability of the solution to nucleation due to an increase in the probability of bond formations between nucleation molecules, which is caused by molecular agitation induced by the frequency of the electric field [17]. In the case of crystallisation of lysozyme (a type of protein), the crystal was found to predominantly nucleate on the cathode side of the electrode [15]. The electric permittivity difference between crystals and solute molecules in a solution, which is caused by the electric field frequency, is the main factor defining the driving force of nucleation (measured as chemical potential), and as the difference becomes larger, the impact of the electric field frequency on the nucleation rate increases [18]. However, nucleation can either be promoted or inhibited based on the ability of the process to surpass the Gibbs free energy barrier associated with nucleation, depending on the orientation of the electric field and the ratio of the dielectric constant between the solution and the crystalline phase [19]. The electric field was believed to cause the dipole of the polar functional group to align in parallel with the direction of the field. In the case of polyamide- 6,6 , the decrease in nucleation rate was due to the disturbance in the antiparallel orientation of the dipole of the amide groups, preventing the formation of a stable structure and, hence, molecular chain packing of the polymer [20]. The prediction of water molecule behaviour with the presence of an electric field using a computational technique later backed up the theory that an electric field causes a structural change in liquid water, making it more organised [21]. Nonetheless, for crystallisation of lysozyme, using an electric field the nucleation rate was successfully controlled through a series of works by Koizumi and co-workers [18,22,23].

The computational molecular modelling method has recently been in demand and has been used to predict the behaviour and properties of molecules [24-27]. In crystallisation, the application of the computational technique is to compliment the hypothesis associated with the nuclei formed during the nucleation process, which is not usually fully understood and not accessible through experimental methods [28-30]. Nucleation is known to have two types of mechanisms-i.e., heterogeneous and homogeneous nucleation. Heterogeneous nucleation usually takes place at a surface of a system-for example, liquid-vapour interface suspended particles and surfaces in the reactor. Homogeneous nucleation could occur in solution, away from the sites for heterogeneous nucleation. Homogenous nucleation is a slower process, with a higher energy barrier than heterogeneous nucleation. For heterogeneous nucleation, the nucleation process grows exponentially with a lower free energy barrier as the surface area of the nucleus in contact with surrounding fluid is less (due to the growth sites on the surfaces) than the area of a nucleus in homogeneous nucleation.

The nucleation mechanism and the aggregation of solute molecules can be explained by the collective behaviour of the molecules as a function of time [31] and can be obtained through molecular dynamics simulations. The nucleation rate is a key factor in characterising the nucleation phenomenon as it is related to the critical size of the nucleus, the supersaturation ratio, and the free energy change in nucleation. Nucleation rate prediction using molecular dynamics simulation was pioneered by Anwar and Boeteng [29]. Nucleation in dynamics simulation was described as the aggregation of particles induced by the Lennard-Jones potential, where the distinctive ordering of particles during clustering represents a nucleation process. The importance of the Coulombic contribution to nucleation was later emphasised [32] and the effect of the force field and the atomic partial charges on 2D nucleation was established for the nucleation process in a limited system [33].

The nucleation of methane hydrate using Gromacs software was evaluated by Yuhara et al. [34] by implementing the modified mean first passage time method and the survival probability method, which was originally used to calculate the vapour-toliquid nucleation. It was reported that the predicted nucleation rate was in good agreement 
(within 20\%) with the experimental data. Amongst other nucleation behaviour predictions using dynamic simulation is the prediction of homogeneous nucleation from the vapour phase by looking into the change in cluster size for nucleation [35]. The prediction of nucleation behaviour, from the prediction of critical radius to the number of molecules forming the critical radius of ammonium perchlorate, was carried out by adopting the Yasuoka and Matsumoto technique [32] using Gromacs software [31]. Their result was in good agreement with the experimental data, even though the predicted nucleation rate was higher than the experimental data. The nucleation rate from the dynamics simulation was determined from the plot of the number of molecules forming the nucleus against simulation time, which was derived from the radial distribution function of the solution. The number of molecules forming the nuclei changes with time until it levels off when the size of the cluster reaches a critical value.

In this work, L-isoleucine was used as the investigated material. L-isoleucine is the most hydrophobic amino acid and exists as zwitterions in solution [36]. Akin to most pharmaceutical products, L-isoleucine exists in crystalline form, which means that it can be produced through the crystallisation process. Many studies have been conducted using amino acids but only a few studies have focused on L-isoleucine. Its zwitterionic behaviour in both a solution and the solid phase makes it an interesting material, and its behaviour would be interesting to assess in the solution when an electric potential is present. The main objective of this study was to determine the nucleation behaviour of L-isoleucine using two crystallisation techniques, i.e., polythermal and isothermal crystallisations, with the presence of an electric potential. The nucleation behaviour of L-isoleucine was also predicted using a molecular dynamics simulation technique, which was then compared with the experimental data from the isothermal crystallisation technique.

\section{Materials and Methods}

\subsection{Materials}

The material used in this experiment was L-isoleucine $\left(\mathrm{C}_{6} \mathrm{H}_{13} \mathrm{O}_{2} \mathrm{~N}\right.$, MW of $\left.131.2 \mathrm{~g} / \mathrm{mol}\right)$ with purity $>99.0 \%$. This material was purchased from Merck Milipore, USA and distilled water was used to make up the solution. L-isoleucine is a zwitterion molecule, with carboxyl $\left(\mathrm{COO}^{-}\right)$and amine $\left(\mathrm{NH}_{3}{ }^{+}\right)$functional groups at one end and an alkyl side chain at the other end. Carbon (graphite, 98\% purity) electrodes with dimensions of $1.0 \mathrm{~cm} \times$ $0.1 \mathrm{~cm} \times 10 \mathrm{~cm}$ were used in the crystalliser to transfer current to the solution. The current to the crystalliser was supplied by a direct current (DC).

L-isoleucine can crystallise in two polymorphic forms, form A and form B. Form A is packed in a monoclinic lattice with space group $P 2_{1}, Z=4, Z^{\prime}=2$, and cell parameters of $\mathrm{a}=9.68, \mathrm{~b}=5.30, \mathrm{c}=13.96 \AA$, and $\beta=96.16^{\circ}$ [37]. Form $\mathrm{B}$ also crystallises in a monoclinic lattice with space group $P 2{ }_{1}$, but with $Z=8$ and $Z^{\prime}=4$. The unit cell dimensions of form $B$ are $\mathrm{a}=9.68, \mathrm{~b}=5.29, \mathrm{c}=28.01 \AA$, and $\beta=98.30^{\circ}$ [38]. Form $\mathrm{A}$ forms dimers in its asymmetric unit, whilst form B contains four molecules in its asymmetric unit. Figure 1 shows the molecular arrangements of L-isoleucine pairs and clusters in their asymmetric units.

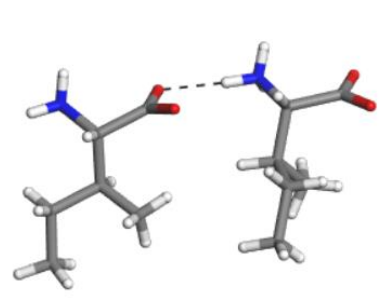

(a)

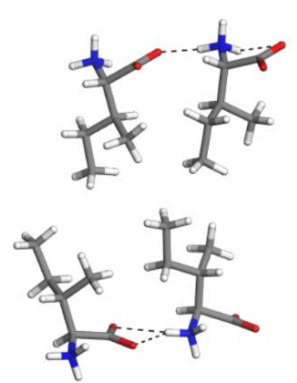

(b)

Figure 1. (a) Asymmetric unit of form A, forming dimer interactions, and (b) the asymmetric unit arrangement of the form B polymorph, consisting of four molecules in an asymmetric unit. 


\subsection{Methods}

The experimental setup for electrocrystallisation is shown in Figure 2. The rig consisted of a $250 \mathrm{~mL}$ jacketed reactor attached to two programmable refrigerated baths so that the desired temperature of the solution for the crystallisation and dissolution process could be effectively achieved. In all the experiments, the volumes of the solution used were $200 \mathrm{~mL}$ and mixing of the solution was carried out by a glass retreat curve impeller. During polythermal crystallisation, only one refrigerated bath was used, and the second refrigerated bath was used for isothermal crystallisation so that sudden quenching of the solution could be achieved. In all experiments, two carbon electrodes were immersed in the solution at a depth of $3 \mathrm{~cm}$ and placed $5 \mathrm{~cm}$ apart while facing each other. Prior to this, the electrodes were cleaned by immersion in acetone, and then rinsed with distilled water and dried in an oven at $40{ }^{\circ} \mathrm{C}$. A direct current was supplied to the solution from the beginning of the experiment until the end of the experiment. The current voltages used for polythermal crystallisation were $5 \mathrm{~V}(1 \mathrm{~V} / \mathrm{cm})$ and $9 \mathrm{~V}(1.8 \mathrm{~V} / \mathrm{cm})$, whilst for isothermal crystallisation, the electric potentials used were $5 \mathrm{~V}(1 \mathrm{~V} / \mathrm{cm})$ and $20 \mathrm{~V}(4 \mathrm{~V} / \mathrm{cm})$. All the experiments were repeated three times to ensure reproducibility.

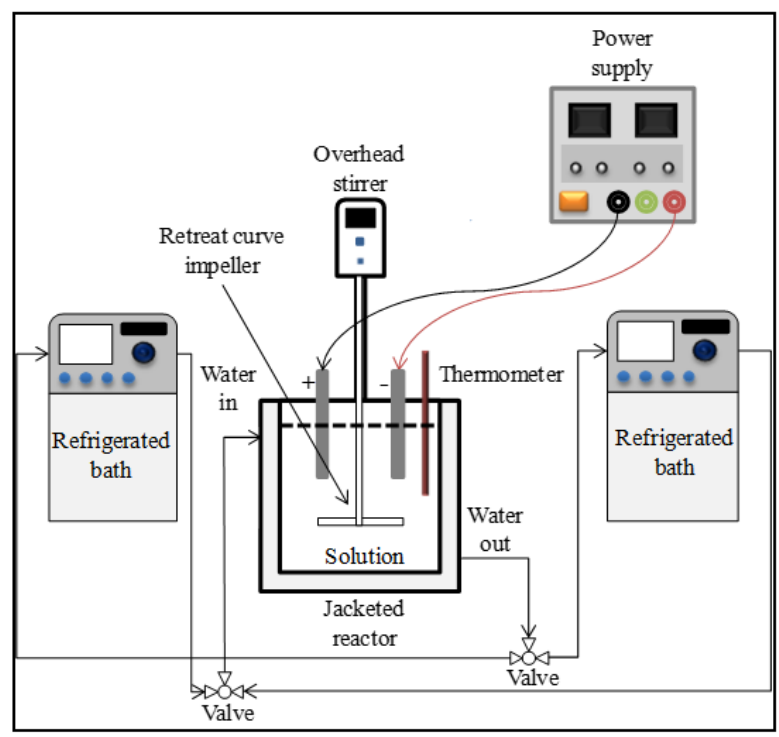

Figure 2. Schematic diagram for the electrocrystallisation experimental rig used in this study. Two refrigerated baths were used for isothermal crystallisation, ensuring that sudden cooling could be achieved.

\subsubsection{Polythermal Crystallisation Experiment}

A known weight of L-isoleucine was mixed in the jacketed reactor, and the solution was stirred using a glass retreat curve impeller. The solution was heated to $85{ }^{\circ} \mathrm{C}$ for at least $30 \mathrm{~min}$ to ensure all crystals were completely dissolved in the water. The electrodes were dipped in the solution, and the power supply was turned on. The solution was cooled to $20^{\circ} \mathrm{C}$ at a known rate for the crystallisation process to occur. The crystallisation temperature, Tcryst, was visually observed and the temperature was noted when small crystals start to appear in the solution. The dissolution temperature, Tdiss, was recorded at the temperature when all the crystals completely dissolved, which was also observed using the visualisation technique. The crystals formed in the solution at the end of the experiment were collected and dried in an oven at $40{ }^{\circ} \mathrm{C}$ for at least $24 \mathrm{~h}$ before being sent for analysis. The L-isoleucine concentrations used in the polythermal experiment were $42 \mathrm{~g} / \mathrm{L}, 44 \mathrm{~g} / \mathrm{L}, 46 \mathrm{~g} / \mathrm{L}$, and $48 \mathrm{~g} / \mathrm{L}$, whilst the cooling and heating rates used were $0.10^{\circ} \mathrm{C} / \mathrm{min}, 0.25^{\circ} \mathrm{C} / \mathrm{min}, 0.5^{\circ} \mathrm{C} / \mathrm{min}$, and $0.7^{\circ} \mathrm{C} / \mathrm{min}$, achieved using the programmable refrigerated bath. 


\subsubsection{Isothermal Crystallisation Experiment}

In this experiment, two programmable refrigerated baths were used for heating and drastic cooling to achieve the desired temperature of the solution (see Figure 2). A known weight of L-isoleucine was dissolved in a $200 \mathrm{~mL}$ solution. The solution was heated to $15^{\circ} \mathrm{C}$ higher than the saturation temperature for $60 \mathrm{~min}$ using the first refrigerated bath to ensure all the crystals were dissolved. Then, the supply of hot water from the first refrigerated bath was stopped and the supply of cold water (set to the desired saturation temperature) from the second refrigerated bath was started. The solution was drastically cooled (rate $1.8^{\circ} \mathrm{C} / \mathrm{min}$ ) to the saturation temperature and the direct current (DC) (measured as the electric potential-e.g., $5 \mathrm{~V}$ ) was supplied to the solution through the carbon electrodes. The temperature was kept constant until the crystal started to form. The time at which the solution reached supersaturation and the crystal started to grow was recorded as the induction time. The experiments were repeated three times for reproducibility using solution concentrations of $42 \mathrm{~g} / \mathrm{L}, 44 \mathrm{~g} / \mathrm{L}, 46 \mathrm{~g} / \mathrm{L}$ and $48 \mathrm{~g} / \mathrm{L}$, and the supersaturation ratios depended on the target temperature sets for each experiment. Detail parameters used in this experiment were included in the Supplementary Materials, Section S1. The crystals formed in the solution were collected and dried in an oven at $40^{\circ} \mathrm{C}$ for $48 \mathrm{~h}$ for characterisation purposes. However, we have not tested the effect of the drying process undertaken in this study on the physico-chemical properties of the crystals. For consistency, the crystals characterised in this study were the crystals collected from the solution only, and not including the crystals attached to the anode and cathode.

\subsubsection{Solid-State Characterisation}

The crystal properties of the polymorphic forms of L-isoleucine, such as the solubility, morphology, melting temperature, and diffraction patterns, were established by Anuar and co-workers $[7,39]$. In this work, the diffraction patterns of the crystals were determined with the intention of determining the type of polymorphic forms produced from the crystallisation techniques and parameters adopted. The crystals were analysed using X-ray powder diffraction (XRPD) (Rigaku Corporation, Tokyo, Japan) with $\mathrm{Cu} \mathrm{K} \alpha$ radiation at $40 \mathrm{~mA}$ and $40 \mathrm{kV}$, with $2 \theta$ between $3^{\circ}$ and $40^{\circ}$, and a rate of $0.01^{\circ} / \mathrm{s}$.

\subsubsection{Computational Technique}

The computational calculations adopted in this work were carried out using Material Studio 4.4 (Dassault Systemes, Shanghai, China). Throughout the simulation, the potential functions used was COMPASS II, a built-in function in Material Studio (MS). The forces on the molecule were calculated from the potential energy expression depending on the forcefield selected. COMPASS II is an established forcefield and is suitable for use with drugs and compounds, including ionic liquids and heterocyclic systems [40]. Its usage has been tested by many previous researchers and was developed based on the first generation of this forcefield, known as COMPASS [41-44].

In this work, simulation for prediction of the nucleation rate for isothermal crystallisation was performed under periodic boundary conditions through the molecular interaction assessment of L-isoleucine in bulk solution. Prior to the construction of an amorphous cell, a three-dimensional water molecule was sketched using a built-in tool available in MS. The L-isoleucine molecule was imported from Cambridge Crystallography Data Centre (CCDC) (Ref. code LISLEU02). Both molecules were optimised to the most stable configuration using COMPASS II as the forcefield. An amorphous cell is an arbitrary cell filled with molecules according to the criteria defined by previous researchers [41,44]. L-isoleucine in water was constructed by packing both molecules into this arbitrary cubic cell. The amount of L-isoleucine and water molecules set in the cubic cell was determined according to the known concentration in water of L-isoleucine, based on its published solubility data [39]. Both L-isoleucine and water molecules were randomly mixed in the arbitrary cell as it allows faster result for the production run in dynamic simulation. Solution supersatura- 
tion was achieved by setting a target temperature for the simulation. Table 1 shows the parameters used in this simulation.

Table 1. The arbitrary cell conditions used in induction time study, showing the number of molecules required to achieve the solution concentration at saturation temperature, Tsat. The temperature, $\mathrm{T}(\mathrm{K})$, is the targeted temperature to create supersaturation conditions.

\begin{tabular}{|c|c|c|c|c|c|}
\hline Concentration $(\mathrm{g} / \mathrm{L})$ & $\begin{array}{c}\text { Number of L-Isoleucine } \\
\text { Molecules }\end{array}$ & $\begin{array}{c}\text { Number of } \\
\text { Water Molecules }\end{array}$ & $\mathrm{T}_{\text {sat }}(\mathrm{K})$ & Supersaturation, S & $\mathbf{T}(\mathrm{K})$ \\
\hline \multirow{4}{*}{48} & \multirow{4}{*}{50} & \multirow{4}{*}{7600} & \multirow{4}{*}{345} & 1.34 & 324.5 \\
\hline & & & & 1.27 & 327.5 \\
\hline & & & & 1.22 & 329.0 \\
\hline & & & & 1.20 & 330.5 \\
\hline \multirow{4}{*}{44} & \multirow{4}{*}{50} & \multirow{4}{*}{8300} & \multirow{4}{*}{339} & 1.34 & 316.0 \\
\hline & & & & 1.28 & 319.5 \\
\hline & & & & 1.25 & 321.5 \\
\hline & & & & 1.23 & 323.0 \\
\hline
\end{tabular}

The cubic cell was optimised, and the energy was minimised and relaxed using the COMPASS II potential function and Ewald summation method for dispersive energy calculations. The optimisation iteration step was set to 1000 steps to ensure accurate results. The equilibration run for this simulation was conducted using an isothermal-isobaric (NPT) thermodynamic ensemble, with a Berendsen thermostat used to control the temperature. The time step used for the equilibration run was $1 \mathrm{fs}$. The production run was simulated for 50 ps $[41,44,45]$ using the NPT (constant number of particles, constant pressure, and constant temperature) ensemble and was temperature- and pressure-controlled using a Berendsen thermostat and a Berendsen barostat, respectively. The target temperature was the supersaturation temperature, as shown in Table 1, and the pressure was set to the vacuum condition, $\mathrm{P}=0 \mathrm{GPa}$. The time step was set to $1 \mathrm{fs}$, and the trajectory was recorded every 1000 steps.

Dynamics simulation for determination of the effect of electric potential on the nucleation rate and its parameters was carried out by introducing electric potential to the system using the polarisation setting in the built-in tool in MS, which was set during the construction of the amorphous cell. The electric potential $(5 \mathrm{~V})$ and temperature $(324.5 \mathrm{~K}$ for the concentration of $48 \mathrm{~g} / \mathrm{L}$ and supersaturation, $\mathrm{S}=1.33$ ) were set prior to simulation. The trajectory frames generated during the production run (every 1 ps) were subjected to the electric potential effect in the dynamic simulation. The simulation parameters with the effect of electric potential were determined at $5 \mathrm{~V}$ using the supersaturation points and concentration sets in Table 1.

\section{Results and Discussion}

\subsection{Polythermal Crystallisation of L-Isoleucine}

Polythermal crystallisation of L-isoleucine was carried out in a batch jacketed reactor with the presence of electric potentials $(5 \mathrm{~V}$ and $9 \mathrm{~V}$ ) and cooling/heating rates, $\mathrm{R}$ with a range of $0.10{ }^{\circ} \mathrm{C} / \mathrm{min}-0.7^{\circ} \mathrm{C} / \mathrm{min}$. The underpinning fundamental theory involving calculation in this section is detailed in the Supplementary Materials, Section S2. Figure 3a depicts the crystallisation and dissolution temperatures recorded in this work. The result shows that the crystallisation temperature, Tcryst, significantly increased with the cooling rate. The application of an electric potential to the solution caused an increase in the onset of nucleation, which produced a higher Tcryst compared to crystallisation without an electric potential (labelled as $0 \mathrm{~V}$ in text and figures). Nonetheless, the change in dissolution temperature, Tdiss for $0 \mathrm{~V}$ with the rate was insignificant, as pointed out in our previous work [39]; however, increases in electric potential recorded higher Tdiss and Tcryst.

The plot of the metastable zone width (MSZW) in Figure 3b, defined as the difference between the saturation temperature and the temperature when spontaneous nucleation 
occurs [46,47], was extracted from the data in Figure 3a at an infinitesimal cooling/heating rate-i.e., $\mathrm{R} \approx 0{ }^{\circ} \mathrm{C} / \mathrm{min}$. The result shows that, even without the effect of the cooling/heating rate, the MSZW decreases as the electric potential supplied to the solution increases. The result also shows that the onset of nucleation can be achieved at a faster rate when the electric potential was increased from $5 \mathrm{~V}$ to $9 \mathrm{~V}$. This may also indicate that electric potential is a factor for the induction of supersaturation of a solution and may prompt nucleation formation. This leads to stable nucleus formation, which can be achieved at higher rates with the presence of an electric field. This also shows that electric potential can reduce the energy barrier for stable nucleus formation by inducing the preferential conformation of solute crystal and causing an increase in the growth of crystallites [15].

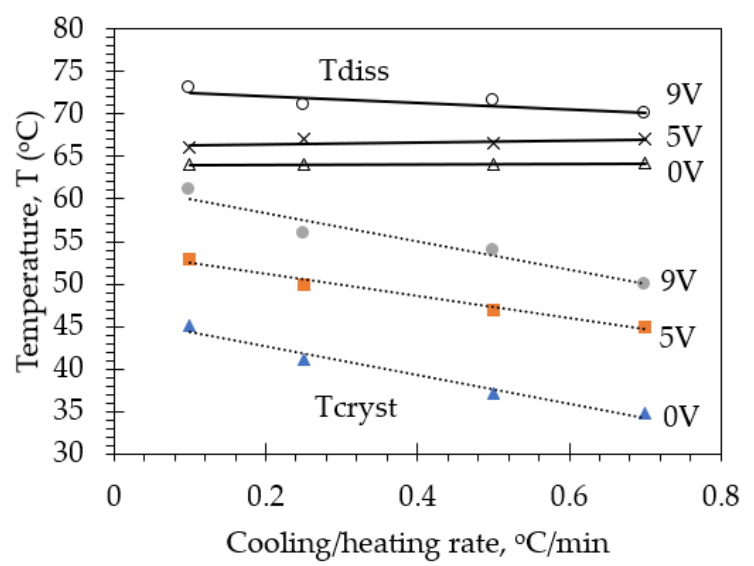

(a)

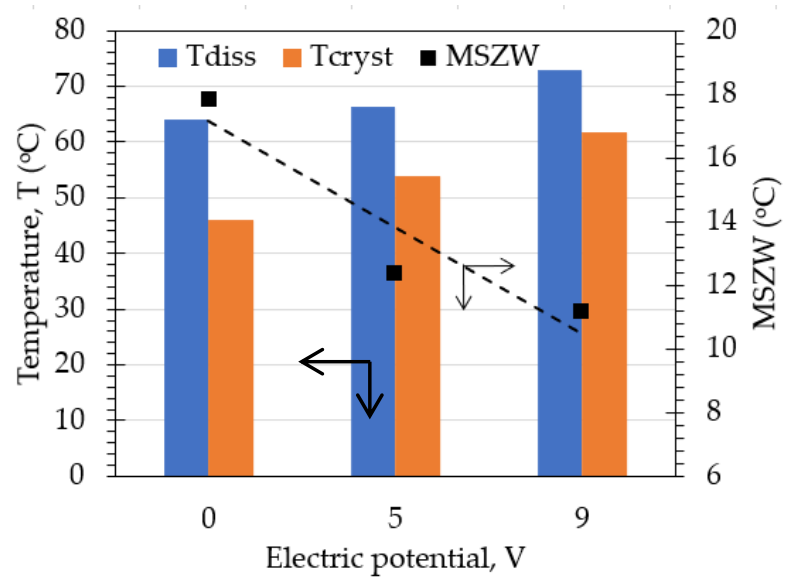

(b)

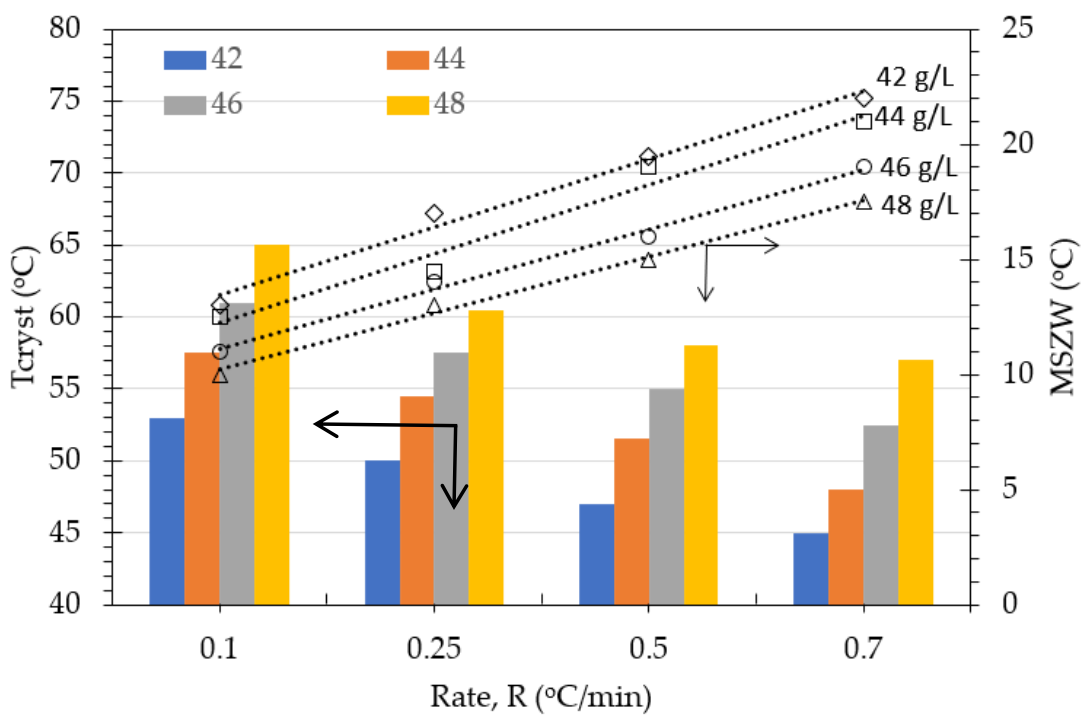

(c)

Figure 3. (a) Temperature of dissolution, Tdiss (shown by the solid line), and temperature of crystallisation, Tcryst (shown by the dashed line), for a solution concentration of $42 \mathrm{~g} / \mathrm{L}$ with the presence of various electric potentials. Data for $0 \mathrm{~V}$ were extracted and recalculated from the data presented by Azmi et al. [39], (b) Tdiss, Tcryst, and metastable zone width (MSZW $=$ Tdiss - Tcryst $)$ of L-isoleucine extracted at an infinitesimally slow rate $\left(\mathrm{R} \approx 0{ }^{\circ} \mathrm{C} / \mathrm{min}\right)$ from the intercepts at the $y$-axis of Figure $4 \mathrm{a}$, representing data at equilibrium. (c) Relationship between the Tcryst, solution concentration and MSZW when a $5 \mathrm{~V}$ electric potential was applied to the solution.

Cooling rates applied to a crystallising solution are also known to change the critical supersaturation, Scrit, of the solution. In this case, Scrit is defined as the ratio of initial solution concentration, $\mathrm{C}(\mathrm{g} / \mathrm{L})$, to equilibrium solution concentration at Tcryst when a stable nucleus with critical size, $\mathrm{r}^{*}$ is formed. Figure $3 \mathrm{c}$ depicts the Tcryst and the MSZW 
results for various solution concentrations for the system with a $5 \mathrm{~V}$ electric potential. The result shows that increasing the cooling rates reduces Tcryst and increases the MSZW for all solution concentrations tested. This means that the low cooling rates of a solution can easily induce the formation of nuclei in the solution, even at low supersaturation. This result is consistent with the results shown for the solution without the electric field. A comparison of the various solution concentrations also showed that the solution with a concentration of $48 \mathrm{~g}$ /L produced the smallest MSZW compared to other lower solution concentrations, which signifies that nucleation can be induced even at lower Scrit. In this case, the fastest nucleation can be obtained from the solution concentration of $48 \mathrm{~g} / \mathrm{L}$ crystallised at a cooling rate of $0.1{ }^{\circ} \mathrm{C} / \mathrm{min}$. This is an advantage for manufacturing applications since the crystallisation process is usually carried out at low cooling rates due to the size of the reactor since nucleation is possible to achieve at higher crystallisation temperatures and since more crystals can be recovered with the aid of an electric field in the solution.

Figure 4 shows the plot of the nucleation rate constant, $k_{n}$, and the order of nucleation, $m$ with concentration for (a) a system without an electric field $(0 \mathrm{~V})$ and $(b)$ for a system with the $5 \mathrm{~V}$ applied to the solution. Comparing between the values in Figure $5 \mathrm{a}, \mathrm{b}$, the nucleation rate constant, $\mathrm{k}_{\mathrm{n}}$, for a $0 \mathrm{~V}$ solution is in the range of $2.38 \times 10^{-8}$ to $6.8 \times 10^{-6}$, whilst for the $5 \mathrm{~V}$ system, the $\mathrm{k}_{\mathrm{n}}$ values are in the range of 0.1 - to 15 -fold larger than for the $0 \mathrm{~V}$ solution. The order of nucleation, $\mathrm{m}$, for the $0 \mathrm{~V}$ solution was slightly higher (2.7-4.4) than the $5 \mathrm{~V}$ solution (3.6-3.8). The nucleation rate constant, $\mathrm{k}_{\mathrm{n}}$, nucleation order, $\mathrm{m}$, and solution supercooling are the function of the nucleation rate, J, with a high dependency of $\mathrm{J}$ on $\mathrm{m}$. Thus, a low $\mathrm{m}$ value means that the dependency of the nucleation rate on the solution's environmental conditions, such as supersaturation and cooling rates, is low. In this case, the $m$ values for the system without and with the electric field are almost within the same order, and hence their effect on the nucleation rate is less apparent. Meanwhile, the $k_{n}$ has a greater impact on the nucleation rate, in which higher $k_{n}$ for the $5 \mathrm{~V}$ solution results in higher J values, consistent with the results shown in Table 2. In the calculation of the nucleation mechanism parameters (refer to Equations (8) and (9) in Supplementary Materials, Section S2) the following values were used: L-isoleucine crystal density, $\rho_{c}=1201 \mathrm{~kg} / \mathrm{m}^{3}$ [48] and the volume shape factor, $\alpha=0.01$ [49] for hexagonal plate-like morphology.

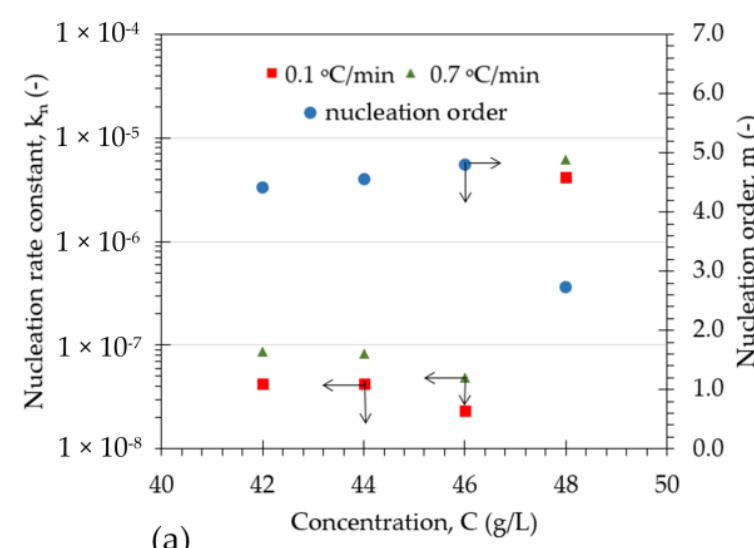

(a)

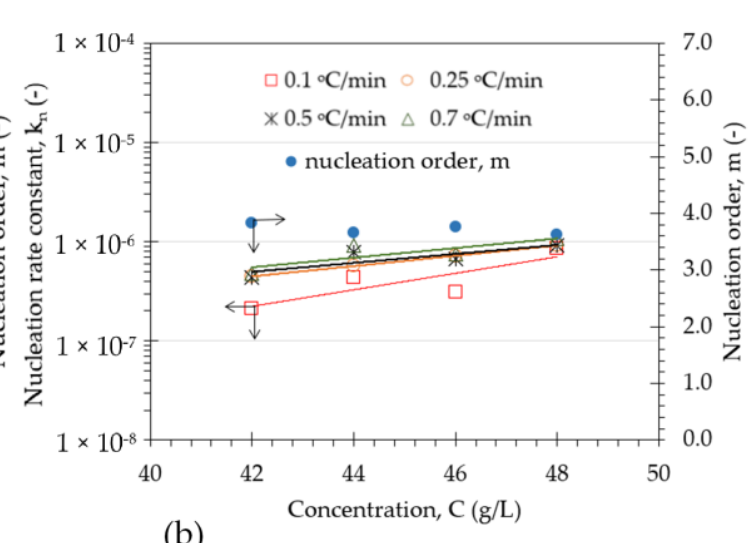

(b)

Figure 4. Nucleation order and nucleation rate constant of L-isoleucine in solution with various heating/cooling rates for (a) $0 \mathrm{~V}$ and (b) $5 \mathrm{~V}$. The plotted values for $0 \mathrm{~V}$ were calculated from data obtained from Anuar and co-workers [7,39]. The blue dots in both figures represent the nucleation order, $\mathrm{m}$ (secondary axes).

The nucleation rate, $\mathrm{J}$ is a measure of how fast the solution nucleates and this result displays a common trait of nucleation in higher supersaturation solutions. Table 2 shows a comparison of the nucleation rate, J, data at various concentrations, cooling rates, and electric potentials. In all cases, $\mathrm{J}$ values are within the order of $10^{25}$ to $10^{26}$ for systems without and with electric potentials (see Table 2). The nucleation rates for systems with 
an electric potential were approximately 1.3- to 1.9-fold higher than the solution without an electric potential. The $9 \mathrm{~V}$ solution had a J value that was 1.1- and 1.3-fold higher than the J value of the $5 \mathrm{~V}$ solution. Thus, crystallisation of L-isoleucine with the presence of an electric potential can be regarded as an advantage to the nucleating solution as it is capable of increasing the nucleation rate of the compound. This result is consistent with the findings in Figure 3.

For solution concentrations between 42 and $46 \mathrm{~g} / \mathrm{L}$, the electric potential doubled the nucleation rates of the solution when the solution's cooling rates were increased from $0.10{ }^{\circ} \mathrm{C} / \mathrm{min}$ to $0.7^{\circ} \mathrm{C} / \mathrm{min}$. Nonetheless, changing the solution cooling rates does not show the same effect for the solution concentration of $48 \mathrm{~g} / \mathrm{L}$, in which the J values are within the range of $1.04 \times 10^{26}$ to $1.38 \times 10^{26}$.

Table 2. Nucleation rate of L-isoleucine from polythermal crystallisation, calculated using Equation (9) in Supplementary Materials, Section S2 for a system without electric potential $(0 \mathrm{~V})$ and a solution with electric potential.

\begin{tabular}{|c|c|c|c|c|c|c|}
\hline & \multicolumn{6}{|c|}{ Nucleation Rate, J (no. of Nuclei $/ \mathrm{m}^{3} \cdot \mathrm{s}$ ) } \\
\hline & $0 \mathrm{~V}^{\mathrm{a}}$ & $5 \mathrm{~V}$ & $9 \mathrm{~V}$ & $0 \mathrm{~V}^{\mathrm{a}}$ & $5 \mathrm{~V}$ & $9 \mathrm{~V}$ \\
\hline Conc., C (g/L) & \multicolumn{3}{|c|}{ Cooling Rate, $\mathrm{R}=0.1\left({ }^{\circ} \mathrm{C} / \mathrm{min}\right)$} & \multicolumn{3}{|c|}{ Cooling Rate, $\mathrm{R}=0.7\left({ }^{\circ} \mathrm{C} / \mathrm{min}\right)$} \\
\hline 42 & $7.15 \times 10^{25}$ & $9.90 \times 10^{25}$ & $1.12 \times 10^{26}$ & $1.47 \times 10^{26}$ & $2.24 \times 10^{26}$ & $2.58 \times 10^{26}$ \\
\hline 44 & $7.69 \times 10^{25}$ & $1.13 \times 10^{26}$ & $1.25 \times 10^{26}$ & $1.51 \times 10^{26}$ & $2.36 \times 10^{26}$ & $2.81 \times 10^{26}$ \\
\hline 46 & $9.53 \times 10^{25}$ & $1.22 \times 10^{26}$ & $1.52 \times 10^{26}$ & $2.03 \times 10^{26}$ & $2.91 \times 10^{26}$ & $3.67 \times 10^{26}$ \\
\hline 48 & $8.51 \times 10^{25}$ & $1.04 \times 10^{26}$ & $1.22 \times 10^{26}$ & $1.27 \times 10^{26}$ & $1.32 \times 10^{26}$ & $1.38 \times 10^{26}$ \\
\hline
\end{tabular}

a The tabulated values at $0 \mathrm{~V}$ were calculated from data obtained in other work [7,39].

\subsection{Isothermal Crystallisation of L-Isoleucine}

Figure 5a shows the relationship between the time taken for the solute to nucleate ( $\tau$, the induction time) and the solution supersaturation with the presence of $5 \mathrm{~V}$ electric potential. The underpinning theory involving the calculation in this section is detailed in the Supplementary Materials, Section S3. The relationship produces two distinguishable lines representing regions of the nucleation mechanism. This finding is consistent with the results reported by previous researchers $[7,50]$ on the existence of the breaking line in the induction time plot, associated with nucleation at low and high supersaturations. Nonetheless, each solution concentration has its supersaturation boundary, ranging between 1.32 and 1.43 (marked by vertical dash lines). The boundary differentiates the type of nucleation mechanism in the solution, in which the nucleation is formed through a heterogeneous nucleation mechanism in solution with high supersaturation, whilst the homogeneous nucleation mechanism dominates in solutions with lower supersaturation [50,51].

At high solution supersaturation, the frequency of solute molecules forming clusters is high with a smaller critical size of nuclei, which successfully reduces the induction time $[51,52]$. This finding is also consistent with the result for the high solution concentration $(48 \mathrm{~g} / \mathrm{L}$, which shows that a shorter induction time is required for nucleation generation, compared to the low solution concentration of $44 \mathrm{~g} / \mathrm{L}$ (see Figure 5a)). The plot also shows that the boundary of the two mechanisms shifted to the higher $S$ value for lower solution concentration, which indicates that lower solution supersaturation can maintain the nucleation and growth through a homogeneous nucleation mechanism at higher supersaturation before the heterogeneous mechanism dominates as the supersaturation increases.

Nucleation is the process of forming a solid phase, in which nuclei aggregate together to form an embryo that will further grow once it reaches a critical size, $\mathrm{r}^{*}$, and forms a crystal. Figure $5 b$ shows the dependency of the critical radius of nuclei, $\mathrm{r}^{*}$, on solution supersaturation for $5 \mathrm{~V}$ solution. Overall, within their respective nucleation mechanism vicinity, i.e., the heterogeneous and homogeneous mechanisms, the value of $r^{*}$ decreases as the supersaturation increases. For the heterogeneous nucleation mechanism (labelled as closed markers) in high supersaturation, $\mathrm{r}^{*}$ does not change significantly for solution 
concentrations of $42 \mathrm{~g} / \mathrm{L}-46 \mathrm{~g} / \mathrm{L}$. However, for the concentration of $48 \mathrm{~g} / \mathrm{L}$, the value of $\mathrm{r}^{*}$ decreases, which indicates that a high supersaturation solution (the presence of a large amount of solute in the solution) initiates the formation of more nuclei with smaller cluster sizes [53]. At lower supersaturation (tagged as open markers), the changes in the $r^{*}$ values with the solution concentration were also insignificant. Smaller $r^{*}$ values were produced through homogeneous nucleation compared to heterogeneous nucleation, which is consistent with the lower Gibbs free energy barrier that must be overcome by the homogeneous mechanism [54]. The same trend was also noted for the number of molecules, $\mathrm{N}^{*}$, forming a critical radius with supersaturation. The $\mathrm{N}^{*}$ values formed through the heterogeneous nucleation mechanism were between 14 and 35 molecules and were associated with $r^{*}$, with values within the range of $8.3 \AA-11.4 \AA$. For the low supersaturation solution, the $\mathrm{N}^{*}$ formed through the homogeneous nucleation was in the range of 3-18 molecules and associated with the $\mathrm{r}^{*}$ values within the range of $4.3 \AA$ - $-11.8 \AA$.

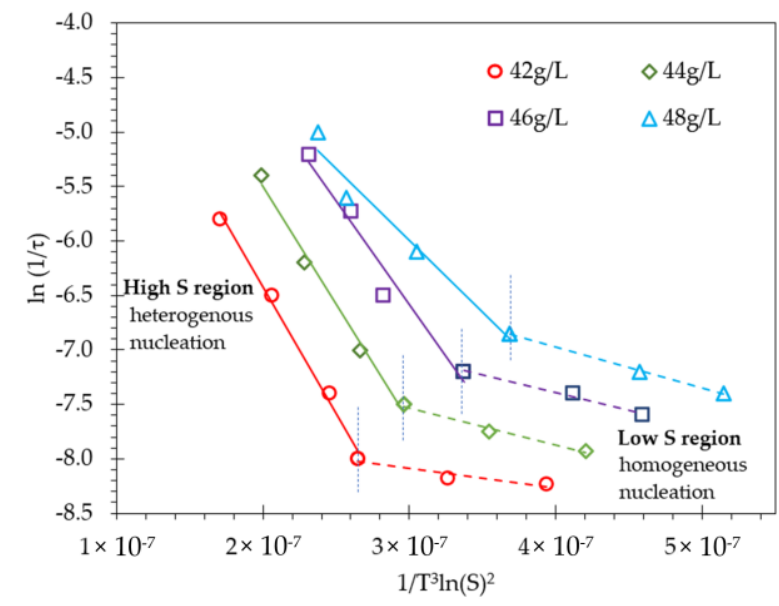

(a)

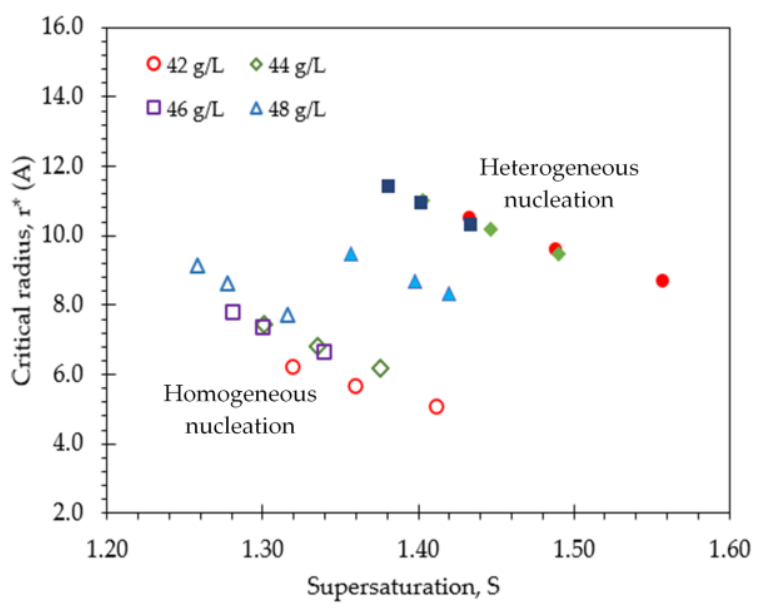

(b)

Figure 5. Isothermal crystallisation of L-isoleucine at $5 \mathrm{~V}$ : (a) nucleation time of solutes in high solution supersaturation and low solution supersaturation, showing that the associated nucleation mechanisms took place in the solution during crystallisation, with the regions marked by vertical dash lines and (b) critical nuclei radius, $\mathrm{r}^{*}$, formed at high supersaturation (closed markers) and low solution supersaturation (open markers) for solution concentrations of $42 \mathrm{~g} / \mathrm{L}-48 \mathrm{~g} / \mathrm{L}$.

Figure 6 shows the comparison of isothermal nucleation parameters between solution at $0 \mathrm{~V}$ and solution with the electric potentials. Overall, the nucleation rate, $\mathrm{J}$ in the homogeneous nucleation are higher compared to the heterogeneous nucleation mechanism (Figure 6a). The application of a $5 \mathrm{~V}$ electric potential to the solution does not significantly increase the J values compared to the $0 \mathrm{~V}$ solution. For the solution with $20 \mathrm{~V}$ potential, low J values were calculated, particularly for high supersaturation solution, whilst for supersaturation $S<1.6$ (low supersaturation), the J values for $20 \mathrm{~V}$ solution are around the same range as the system with the $0 \mathrm{~V}$ and $5 \mathrm{~V}$ electric potentials (see Figure 6a). This result shows that the effect of the electric potential on the solution crystallisation through the isothermal nucleation is less significant.

Further analysis on the critical radius of nuclei, $\mathrm{r}^{*}$, growing into a crystal shows no consistent trend with the increase in electric potential (Figure 6b). The crystallisation of L-isoleucine through a homogeneous nucleation mechanism that takes place with lower solution supersaturation produces a more scattered size range of $\mathrm{r}^{*}$ (ranging from $6 \AA$ to 13.7 $\AA$ ). Nonetheless, the effect of a $20 \mathrm{~V}$ electric field on the solution produces $\mathrm{r}^{*}$ values between $7.1 \AA$ and $8.2 \AA$ for nuclei, generated through the heterogeneous mechanism, and between $11.5 \AA$ and $12.7 \AA$ through the homogeneous nucleation mechanism. The results presented here are consistent with the findings of Saban et al. [55], in which the application of electric potential further reduces the Gibbs free energy of formation, which results in easier nucleation formation. Thus, for this work, the $\mathrm{r}^{*}$ decreases when the solution supersaturation, $\mathrm{S}$, increases, regardless of the amount of electric potential applied 
to the solution. This result is consistent with the observations reported in $[50,56]$ and with the findings in Figure 5 for variation in solution concentration.

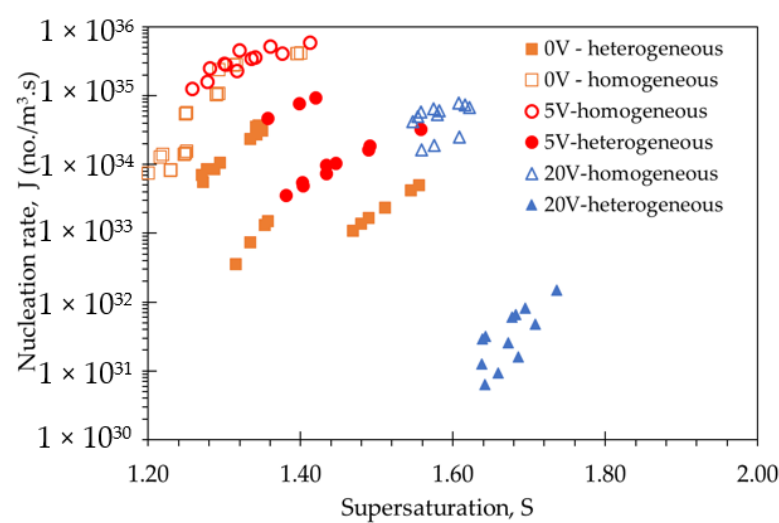

(a)

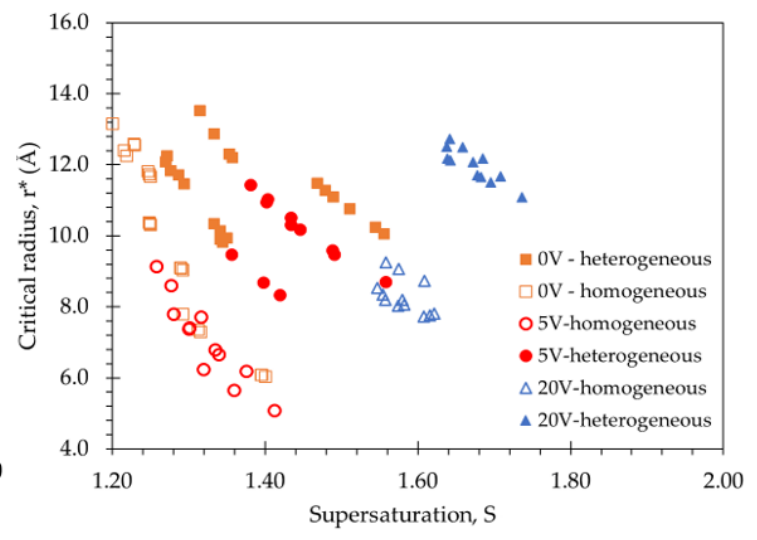

(b)

Figure 6. Nucleation parameters from isothermal nucleation due to variation in the electric potential applied to the solution. (a) Nucleation rate and (b) critical radius, $\mathrm{r}^{*}$, variations with supersaturation.

Comparison of the nucleation rate, J, for the aqueous L-isoleucine solution using the polythermal and isothermal crystallisation methods in solution without and with the effect of electric potential are depicted in Figure 7a,b. In general, the results for both solution systems $(0 \mathrm{~V}$ and $5 \mathrm{~V})$ show that the nucleation rates of L-isoleucine using the isothermal crystallisation technique is in the order of $10^{10}$ faster than the nucleation rate using the polythermal crystallisation method. For the $5 \mathrm{~V}$ solution, the nucleation rate under the homogeneous mechanism are between 6 and 36 times faster than the nucleation rate through the heterogeneous nucleation. This serves as an added advantage to this system since crystallisation in a low supersaturation solution can produce a bettercontrolled crystal morphology and size [47] and higher purity crystals [57]. Nonetheless, it is still important to investigate the effect of electric potential on the morphology and polymorphism of the L-isoleucine molecule, which will be discussed in a later section.

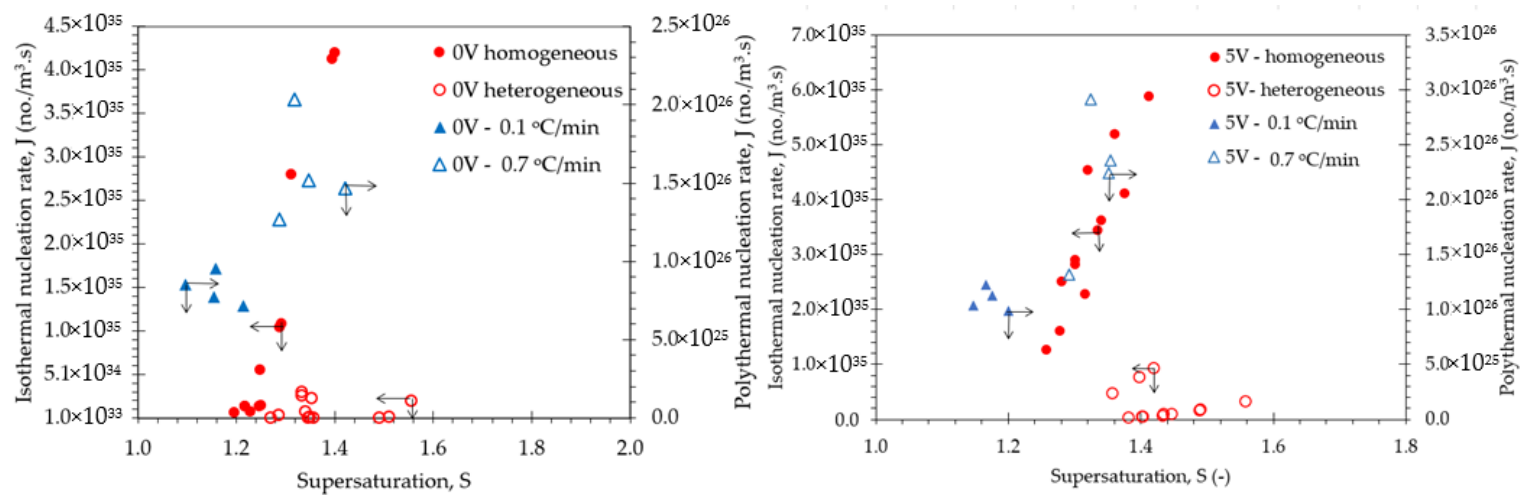

Figure 7. Nucleation rate, J, of polythermal and isothermal crystallisation of L-isoleucine in the aqueous phase under different solution conditions: (a) $0 \mathrm{~V}$ and (b) $5 \mathrm{~V}$.

In the case of the polythermal crystallisation technique, the finding in this study (Figure 7) agrees with a study by Koizumi et al. [22], where the nucleation rate for crystal formation increased due to the application of an electric potential. The same observation was also reported by Saban et al. [55], where the induction time for nucleation was found to decrease as the electric potential applied to the solution increased. In this case, the application of an electric potential caused the electrolysis process to occur. The reduction process took place at the cathode where the ions gained electrons and the reduced form was deposited and remained in the solution, whilst the oxidation process occurred at 
the anode, where anions move towards the anode and lose electrons, forming atoms or molecules [58]. Water exists as $\mathrm{H}_{3} \mathrm{O}^{+}$and $\mathrm{OH}^{-}$ions in solution due to self-ionisation. Its high affinity causes it to deionise much more easily, which reduced at the cathode and oxidises at the anode, releasing $\mathrm{H}_{2}$ and $\mathrm{O}_{2}$ gas, respectively. L-isoleucine, on the other hand, is a hydrophobic molecule due to the presence of the hydrophobic alkyl group and tends to aggregates close to each other to reduce the contact with water [39]. When $\mathrm{H}_{3} \mathrm{O}^{+}$ and $\mathrm{OH}^{-}$ions are deionised near the vicinity of the electrodes, this creates a competition for L-isoleucine to form a hydrogen bond with water. Apart from L-isoleucine molecules being more prone to clustering in water [39], the 'loss' of water molecules to form hydrogen bonds with L-isoleucine molecules due to the reduction process at the electrodes induces the solution supersaturation, hence the nucleation of L-isoleucine molecules, reflecting the results obtained in this study. The self-ionisation of water does not cause proton transfer from the $\mathrm{NH}_{3}{ }^{+}$to the $\mathrm{COOH}^{-}$to form salt L-isoleucine crystals in the solution. The XRPD analysis carried out in the next section proves that the L-isoleucine molecules remained in the zwitterionic form, which is the stable solid form.

\subsection{Characterisation of L-Isoleucine Crystals from Polythermal and Isothermal Crystallisation}

L-isoleucine crystals recovered from both the polythermal and isothermal crystallisation techniques were characterised for phase determination of the crystal. L-isoleucine has two polymorphic forms, i.e., form A and form B, and the detailed characterisations of these forms have been presented elsewhere [7]. L-isoleucine crystallises in a hexagonal plate-like shape, in which the shape of both forms cannot be readily distinguished by the naked eyes. They can be differentiated, however, through measurement of the apex angle of the crystals, where form $\mathrm{A}$ has an apex angle of $128.1^{\circ}$ and form $\mathrm{B}$ has a smaller apex angle of $121.8^{\circ}$. For both crystallisation techniques employed with $5 \mathrm{~V}$ and $9 \mathrm{~V}$ electric fields, no significant change in the shape of L-isoleucine was noted. However, the application of a high electric field to the solution, such as a $20 \mathrm{~V}$ one, produces clumps of crystals with many undefined shapes. The morphology of the crystals extracted from this study, showing the differences between form A and form B, and the crystal shapes at various electric field applied can be obtained as Supplementary Materials, Section S4.

Table 3 shows a summary of the XRPD results for crystals grown using polythermal crystallisation techniques. The result shows that crystallisation using the polythermal technique resulted in uncontrollable crystal output, in which the process was prone to produce mixtures of form A and form B of L-isoleucine polymorphs. Form A is a stable form, whilst form B is a metastable form, and they are enantiotropically related [7]. For polythermal crystallisation, the form B polymorph was produced at low solution concentration $(42 \mathrm{~g} / \mathrm{L})$ and high cooling rates $\left(0.25^{\circ} \mathrm{C} / \mathrm{min}-0.70{ }^{\circ} \mathrm{C} / \mathrm{min}\right)$, and the results were fairly consistent for both $5 \mathrm{~V}$ and $9 \mathrm{~V}$ solutions. Compared with the system without the electric field $(0 \mathrm{~V})$ for a solution concentration of $44 \mathrm{~g} / \mathrm{L}$ [7], form B was produced from the solution with the cooling rates of more than $0.25^{\circ} \mathrm{C} / \mathrm{min}$, whilst form A was produced by the solution cooled at $0.10^{\circ} \mathrm{C} / \mathrm{min}$. The application of an electric field to the solution might disturb the kinetic route for form B formation in $44 \mathrm{~g} / \mathrm{L}$ solutions and hence produced mixtures of $\mathrm{A}$ and $\mathrm{B}$ in the solution. Nonetheless, lowering the solution concentration (cooling rates between $0.25^{\circ} \mathrm{C} / \mathrm{min}$ and $0.7^{\circ} \mathrm{C} / \mathrm{min}$ ) successfully produced a single form of polymorph B. On the other hand, Table 4 shows that form B has successfully produced from the isothermal crystallisation, regardless of the supersaturation and the intensity of the electric potential used.

The analysis of the results carried out in Figure 3 shows that at a solution concentration, $\mathrm{C}$, of $42 \mathrm{~g} / \mathrm{L}$ and cooling rates between 0.25 and $0.7^{\circ} \mathrm{C} / \mathrm{min}$, the calculated MSZWs are amongst the highest and with the lowest Tcryst values recorded compared to the other parameters used in this study. These parameters could be the solution's environmental conditions prompting for the formation of the metastable form and some changes in parameters result in solution mediated transformation to the more stable form $\mathrm{A}$. In the case of the isothermal crystallisation technique, the crystals produced were the form B poly- 
morph regardless of the crystallisation parameters used-i.e., the solution supersaturation, the type of nucleation mechanism and the intensity of the electric potential applied to the solution.

Table 3. Tabulated data for X-ray powder diffraction (XRPD). Characterisation result for the crystal product collected from polythermal crystallisation experiment.

\begin{tabular}{cccccc}
\hline \multirow{2}{*}{ Electric Potential } & Rate, $\mathbf{R}\left({ }^{\circ} \mathbf{C} / \mathbf{m i n}\right)$ & \multicolumn{4}{c}{ Solution Concentration } \\
\cline { 3 - 6 } & 0.1 & $\mathbf{4 2} \mathbf{~ g} \mathbf{L}$ & $\mathbf{4 4} \mathbf{~ g} / \mathbf{L}$ & $\mathbf{4 6} \mathbf{~ g} \mathbf{L}$ & $\mathbf{4 8} \mathbf{~} / \mathbf{L}$ \\
\hline & 0.25 & $\mathrm{~A}+\mathrm{B}$ & $\mathrm{A}+\mathrm{B}$ & $\mathrm{A}+\mathrm{B}$ & $\mathrm{A}+\mathrm{B}$ \\
$5 \mathrm{~V}$ & 0.5 & $\mathrm{~B}$ & $\mathrm{~A}+\mathrm{B}$ & $\mathrm{B}$ & $\mathrm{A}+\mathrm{B}$ \\
& 0.7 & $\mathrm{~B}$ & $\mathrm{~A}+\mathrm{B}$ & $\mathrm{B}$ & $\mathrm{A}+\mathrm{B}$ \\
& 0.1 & $\mathrm{~A}+\mathrm{B}$ & $\mathrm{A}+\mathrm{B}$ & $\mathrm{A}+\mathrm{B}$ & $\mathrm{A}+\mathrm{B}$ \\
& 0.25 & $\mathrm{~B}$ & $\mathrm{~B}$ & $\mathrm{~A}+\mathrm{B}$ & $\mathrm{A}+\mathrm{B}$ \\
& 0.5 & $\mathrm{~B}$ & $\mathrm{~A}+\mathrm{B}$ & $\mathrm{A}+\mathrm{B}$ & $\mathrm{A}+\mathrm{B}$ \\
& 0.7 & $\mathrm{~B}$ & $\mathrm{~A}+\mathrm{B}$ & $\mathrm{A}+\mathrm{B}$ & $\mathrm{B}$ \\
\hline
\end{tabular}

Table 4. Polymorphs of L-isoleucine grown from the isothermal crystallisation experiments.

\begin{tabular}{ccccc}
\hline \multirow{2}{*}{$\begin{array}{c}\text { Electric } \\
\text { Potential }\end{array}$} & \multicolumn{4}{c}{ Isothermal Crystallisation } \\
\cline { 2 - 5 } & $\begin{array}{c}\text { Homogeneous } \\
\text { Mechanism }\end{array}$ & $\begin{array}{c}\text { Heterogeneous } \\
\text { Mechanism }\end{array}$ & $\begin{array}{c}\text { Homogeneous } \\
\text { Mechanism }\end{array}$ & $\begin{array}{c}\text { Heterogeneous } \\
\text { Mechanism }\end{array}$ \\
\hline $5 \mathrm{~V}$ & $\mathrm{~S}=1.41$ & $\mathrm{~S}=1.49$ & $\mathrm{~S}=1.34$ & $\mathrm{~S}=1.42$ \\
\hline $\mathrm{B}$ & $\mathrm{B}$ & $\mathrm{B}$ & $\mathrm{B}$ \\
\hline $20 \mathrm{~V}$ & $\mathrm{~S}=1.62$ & $\mathrm{~S}=1.74$ & $\mathrm{~S}=1.61$ & $\mathrm{~S}=1.70$ \\
\hline
\end{tabular}

\subsection{Dynamic Simulation for Nucleation Rate Prediction}

Dynamic simulations of L-isoleucine to predict the nucleation rate of isothermal crystallisation, without and with the effect of electric potential, were carried out using the protocol described in Section 2.2.4. The underpinning theory involving simulation parameters and calculations in this section is detailed in the Supplementary Materials, Section S5. Figure 8 shows a snapshot of different configurations of the cell containing L-isoleucine molecules with a concentration of $44 \mathrm{~g} / \mathrm{L}$ and supersaturation, S, of 1.48. Figure 8a shows snapshots of the arbitrary cell for the production run at 0 ps, whilst Figure $8 \mathrm{~b}$ shows the arbitrary cell containing L-isoleucine and water during the dynamic simulation for the production at a time of 5 ps. In both figures, the L-isoleucine molecules were coloured in yellow for clarity since the cell contains many molecules. Water molecules are in the original colours of red and white, signifying the oxygen and hydrogen atoms, respectively.

At the start of the simulation (Figure 8a), L-isoleucine molecules were more dispersed in the cell since the molecules require time to interact with molecules and start to aggregate. At the simulation of $5 \mathrm{ps}$, the molecules started to aggregate closer to each other, as shown in Figure $8 \mathrm{~b}$ by the white circle. The same occurrence was also observed by previous researchers $[31,43,44]$, where the materials investigated seemed to be aggregated closer to each other until they reached optimum stability. The time taken for the molecules to stabilise depends on the condition of the system, such as the initial molecular configuration of the cell, the size of the cell, the number of molecules, the type of molecules, the running temperature, and the force field applied to the cell. Since L-isoleucine is a hydrophobic molecule, it tends to avoid interaction with water molecules and aggregates with other L-isoleucine molecules to form clusters and hence induce nucleation. This observation is consistent with the experimental findings in [39]. The effect of $5 \mathrm{~V}$ of electric potential on the nucleating solution was also simulated using a built-in technique called polarisation 
protocol, as described in Section 3.2. Figure 8c shows the snapshot of the cell at 5 ps, for a solution supersaturation of 1.40 and with the effect of $5 \mathrm{~V}$ of electric potential, and aggregates of L-isoleucine were also seen (shown by the white circles). The work by Jung et al. [21] has shown that the electric potential causes the structure of the ice-like water become more organised due to the structural changes in water. The dipole moment of water causes water molecules are capable to obtain extra energy supplied through the interactions with the electric potential. The energy supplied by the electric potential is greater than the kinetic energy in water and thus enables the structural orderliness in liquid water to be induced.

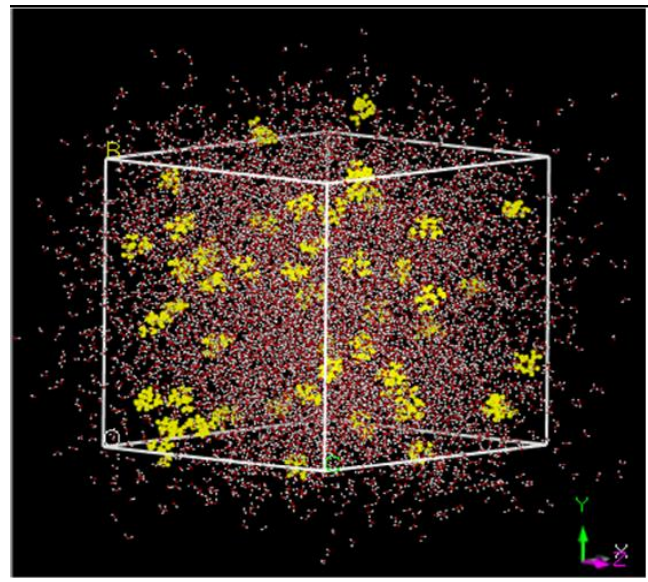

(a)

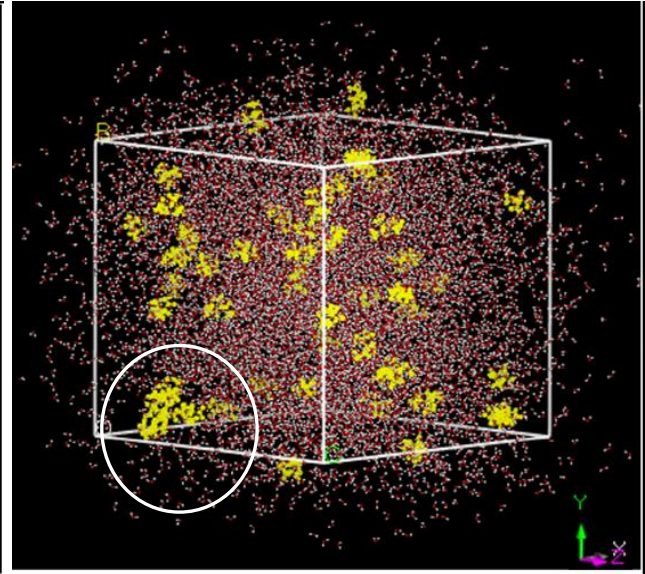

(b)

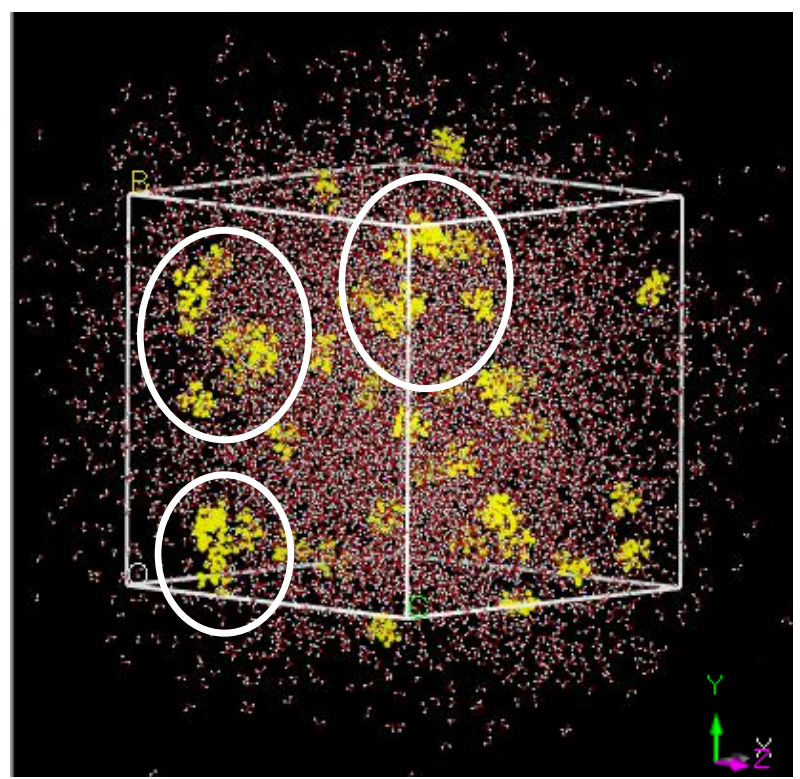

(c)

Figure 8. Snapshots of the cell showing the evolution of the simulation containing L-isoleucine and water molecules during the production run. (a) Cell at 0 ps, (b) cell at 5 ps for the $44 \mathrm{~g} / \mathrm{L}$ concentration and supersaturation ratio of 1.28 , and (c) cell at 5 ps for the solution with a $44 \mathrm{~g} / \mathrm{L}$ concentration and supersaturation of 1.40 with the presence of a $5 \mathrm{~V}$ electric potential.

Prediction of nucleation rate and its associated parameters was carried out by analysis of every frame of the simulation, which was also used by previous researchers [31,35]. The analysis was carried out to obtain the RDF for L-isoleucine molecules where the structural changes for the molecules in the cell were calculated. Figure 9 shows the RDF graph for $0 \mathrm{~V}$ and $5 \mathrm{~V}$ for the concentration of $44 \mathrm{~g} / \mathrm{L}$ at a supersaturation ratio of 1.48 
and at $50 \mathrm{ps}$ time frames. In Figure $9 \mathrm{a}, \mathrm{b}$, strong peaks were present mainly in the region of radius less than $4 \AA$. In general, peaks of the RDF curve that lies within $3.5 \AA$ are caused by the hydrogen bonding and also chemical bonding, while the curve that lies outside of $3.5 \AA$ comes from the van der Waals and Coulombic interactions [44], which in this case is consistent with the result in Figure 9. The nucleation parameters were determined through further analysis of these data for the calculation of the number of molecules present within the pre-determined vicinity. The data were extracted from all the visible peaks in Figure 10 for the radius range between $5 \AA$ and $20 \AA$. The insets in Figure 9 are examples of the small peaks, which will need to be included in the calculation. The number of molecules present within a predetermined threshold (n) were calculated from the integral of Equation (16) (see Supplementary Materials, Section S5), which gives the number of molecules encloses between two spheres, which is the volume occupied between two adjacent radii. This technique, which is known as the Yasuoka-Matsumoto method [35] requires the total number of molecules at a radius from the central atom (denoted as $\mathrm{N}>$ number of molecules) collectively added to the number of smaller radii that were previously identified. Figure 10 shows the number of molecules calculated within the radius vicinity from the central atom, denoted as $\mathrm{N}>$ number of molecules associated with the radius from the central atom.

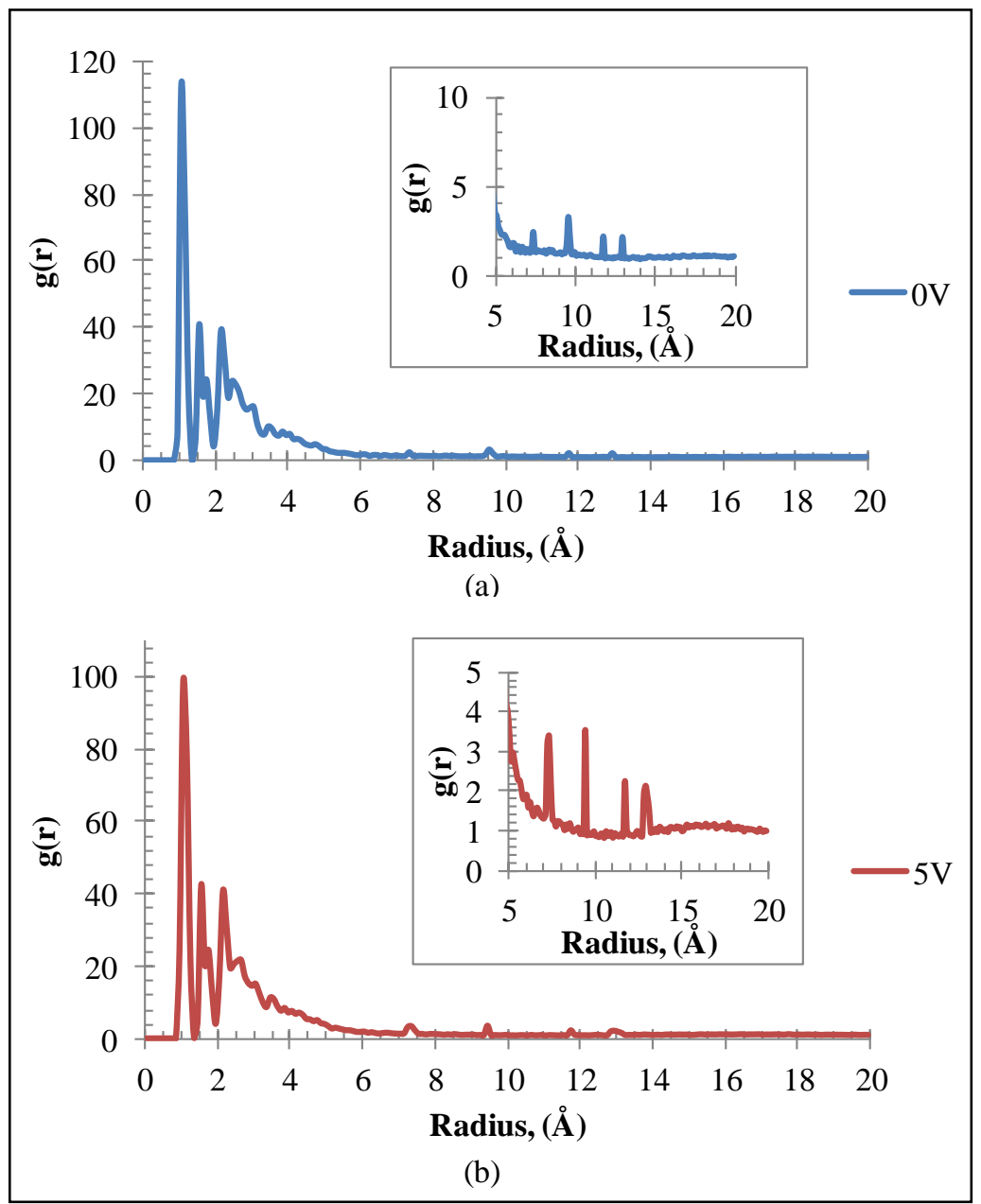

Figure 9. The RDF of the $44 \mathrm{~g} / \mathrm{L}$ system for a simulation time of $50 \mathrm{ps}$ with (a) an electric potential of $0 \mathrm{~V}$ at supersaturation of 1.28 and $(\mathbf{b})$ with an electric potential of $5 \mathrm{~V}$ at supersaturation of 1.40. The insets are the enlarged results for interaction distance between $5 \AA$ and $20 \AA$. 


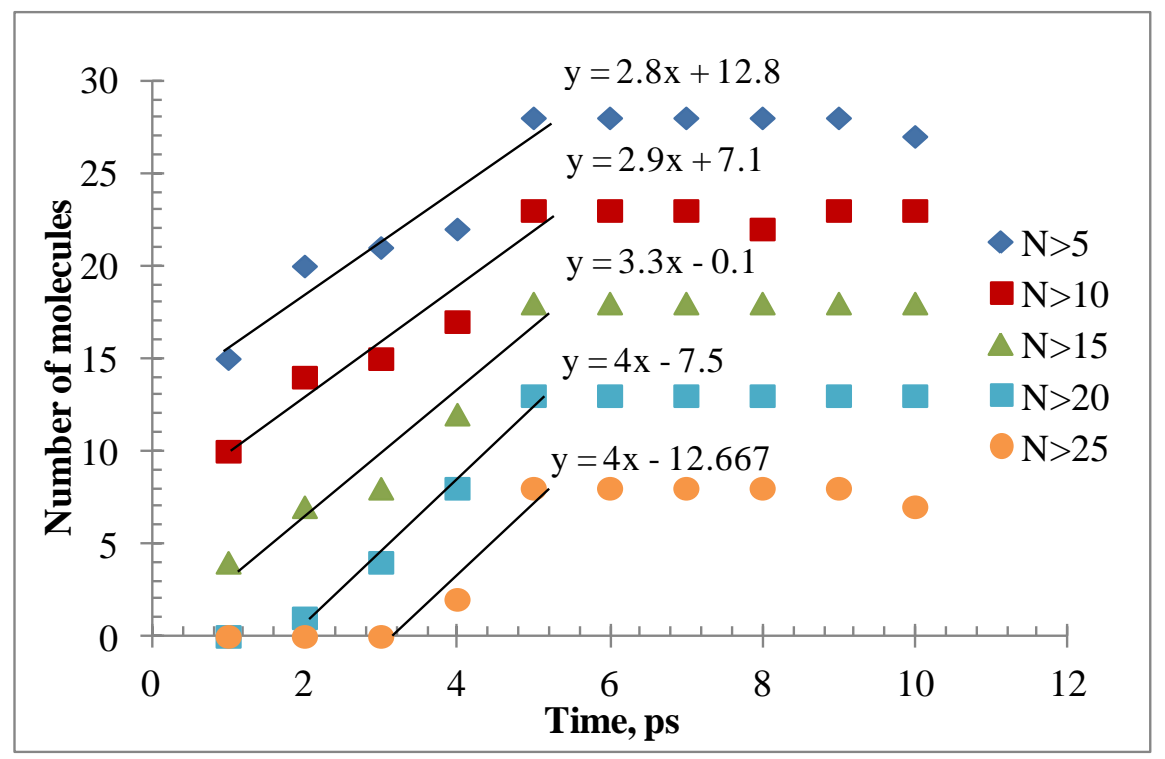

Figure 10. Evolution of the number of molecules forming clusters with time for the solution concentration of $44 \mathrm{~g} / \mathrm{L}$ at $\mathrm{S}=1.28$, without the presence of electric potential.

The slope of the plot was divided by the volume of the cell and was equal to the nucleation rate. The number of molecules starts to level off when the aggregated molecules do not increase in size, and this is when the nuclei reach the critical size of $r^{*}$. From Figure 10, the number of molecules seems to be constant at a simulation time of 5 ps for all boundary sets for the total number of molecules. For instance, for $\mathrm{N}>20$ at $5 \mathrm{ps}$, there are 13 molecules of L-isoleucine available between $\mathrm{N}>20$ and $\mathrm{N}>25$. The boundaries of $\mathrm{N}>20$ and $\mathrm{N}>25$ were determined based on the two enclosed radii from Figure 9. For $\mathrm{N}>20$, the slope of the data set before it became constant was four (see the linear equation for the slope). Dividing this number by the volume of the cell gives the critical number of molecules, $\mathrm{N}^{*}$, associated with the critical radius equal to 40 molecules, and the $\mathrm{r}^{*}$ equal to $9.55 \AA$. The data for each of the conditions in this simulation were extracted, and the results are shown in Figure 11. Comparison between simulated and experimentally derived $\mathrm{N}^{*}$ values (Figure 11a) shows good agreement, particularly for the $44 \mathrm{~g} / \mathrm{L}$ solutions with a $5 \mathrm{~V}$ electric potential. The rest of the systems show that the experimental $\mathrm{N}^{*}$ values are higher than the predicted values. For $r^{*}$, most of the simulated values were within the same range as the values determined experimentally by the isothermal crystallisation technique (see Figure 11b). Further analysis of the data shows that the predicted nucleation rate, J, was on average 300-fold higher than the experimentally determined J. The same observation was made by Shim et al. [31], where the simulated value for the nucleation of ammonium perchlorate was higher than the experimental result. This has shown that the conditions and parameters used in the simulation can predict the values for both $\mathrm{N}^{*}$ and $\mathrm{r}^{*}$ but overpredict the nucleation rate of the isothermal process. This could be because the nucleation conditions obtained using molecular modelling were simulated in a prescribed process (i.e., for the nucleation of ammonium perchlorate was higher than the experimental result), whilst the experimental result was calculated based on real solution conditions. The real solution conditions could mean that nucleation can be affected by homogenous, heterogenous, and secondary nucleation, which were not considered in this system. 


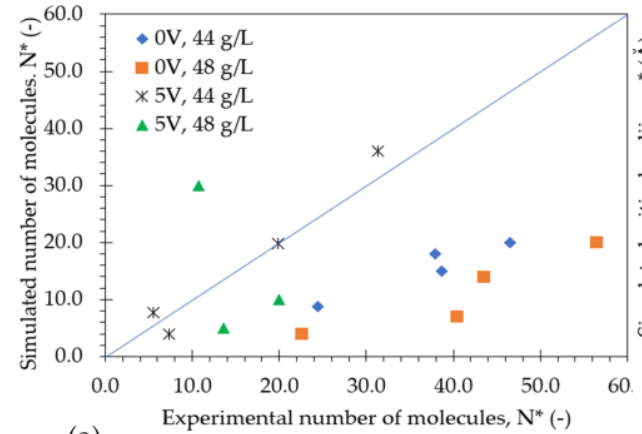

(a)

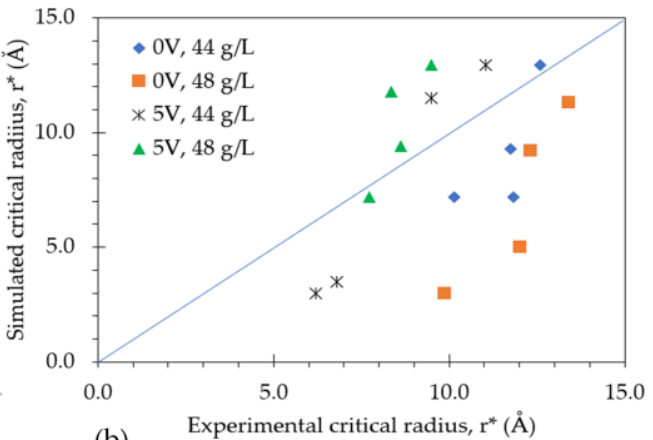

(b)

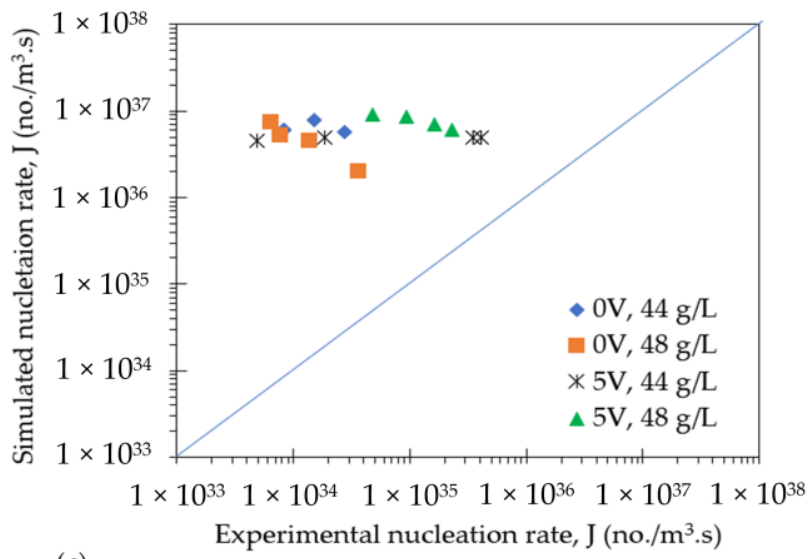

(c)

Figure 11. Comparison between experimental and simulated values for (a) the critical number of molecules, $\mathrm{N}^{*},(\mathbf{b})$ critical radius, $\mathrm{r}^{*}$, and (c) nucleation rate, $\mathrm{J}$.

\section{Conclusions}

The effect of electric potentials on a crystallising solution was measured through two crystallisation techniques, i.e., polythermal crystallisation and isothermal crystallisations, and the results showed that electric potential can induce crystallisation and increase the nucleation rates of a crystallising solution. Nonetheless, in both cases, increasing the intensity of the electric field did not have a significant impact on the nucleation kinetics.

Application of $5 \mathrm{~V}-9 \mathrm{~V}$ electric potentials during polythermal crystallisation increased the nucleation rates of L-isoleucine almost 2-fold compared to the solution without the electric potential, and high cooling rates can further double the nucleation rates. Supersaturation measured as a function of cooling rate and the solution concentration had a significant impact on the nucleation rate, consistent with the findings of previous researchers. For isothermal crystallisation, nucleation took place during two types of mechanisms, i.e., homogeneous nucleation and heterogeneous nucleation, in which the nucleation rate was higher for homogeneous nucleation (i.e., at low solution supersaturation) compared to heterogeneous nucleation. Application of an electric potential to the solution can further increase the rate by up to 12-fold, but caution must be exercised when applying the electric potential to the crystallising solution through the isothermal technique as a higher electric potential can cause a significant reduction in the nucleation rate. Isothermal crystallisation successfully produced a single form B L-isoleucine polymorph. Polythermal crystallisation produced mixtures of form A and form B, except at high cooling rates and for a low supersaturation solution, in which form B was also produced. The prediction of nuclei clustering for nucleation formation was successfully carried out through molecular dynamics. The simulated nucleation parameters, i.e., the critical radius, $\mathrm{r}^{*}$, and the number of molecules associated with the critical radius, $\mathrm{N}^{*}$, were in good agreement with the experimental results. The simulated nucleation rate, however, was about 300-fold higher than the experimental 
values, which could be due to the effect of the difference in the solution environmental conditions set between the simulation and the real conditions.

Supplementary Materials: The following are available online at https:/ / www.mdpi.com/article / 10.3390/cryst11060620/s1, Figure S1: Polymorphic forms of L-isoleucine, showing form A and form B in a solution; Figure S2: The shape of L-isoleucine crystal shape grown in $5 \mathrm{~V}, 9 \mathrm{~V}$ and 20 V solutions; Figure S3: Radial distribution function (RDF) showing the positions of atoms in the cell from an arbitrary reference atom; Table S1: Detailed parameters used for induction time determination in isothermal crystallisation experiments; S2: Theoretical background: nucleation parameter determination for polythermal crystallisation and Section S3: Theoretical background: nucleation parameter determination for isothermal crystallisation.

Author Contributions: Conceptualisation, N.A., N.F.A.B. and M.N.N.; data curation, N.S.M.A. and N.A.; formal analysis, N.S.M.A., N.A. and M.F.O.; funding acquisition, N.A.; investigation, N.S.M.A.; methodology, N.A., N.F.A.B. and M.N.N.; project administration, N.A. and N.F.A.B.; resources, N.A.; software, N.A.; supervision, N.A. and N.F.A.B.; validation, N.S.M.A.; visualisation, N.A.; writingoriginal draft, N.S.M.A.; writing-review and editing, N.A., M.F.O., N.F.A.B. and M.N.N. All authors have read and agreed to the published version of the manuscript.

Funding: This research was funded by the Ministry of Higher Education, Malaysia, grant number 600-RMI/ERGS 5/3(29/2012).

Institutional Review Board Statement: Not applicable.

Informed Consent Statement: Not applicable.

Data Availability Statement: The data presented in this study are available in [insert article or supplementary material here].

Acknowledgments: The authors would like to express their gratitude to Universiti Teknologi MARA, Malaysia, for the facilities provided and to the Ministry of Higher Education, Malaysia for funding this work.

Conflicts of Interest: The authors declare no conflict of interest. The funders had no role in the design of the study; in the collection, analyses, or interpretation of data; in the writing of the manuscript; or in the decision to publish the results.

\section{References}

1. Krishna, R.; Yu, L. Biopharmaceutics Applications in Drug Development; Springer Science \& Business Media: New York, NY, USA, 2007.

2. Nagy, Z.K.; Fevotte, G.; Kramer, H.; Simon, L.L. Recent advances in the monitoring, modelling and control of crystallization systems. Chem. Eng. Res. Des. 2013, 91, 1903-1922. [CrossRef]

3. Bryant, M.J.; Rosbottom, I.; Bruno, I.J.; Docherty, R.; Edge, C.M.; Hammond, R.B.; Peeling, R.; Pickering, J.; Roberts, K.J.; Maloney, A.G. "Particle Informatics": Advancing our understanding of particle properties through digital design. Cryst. Growth Des. 2019, 19, 5258-5266. [CrossRef]

4. Genceli, F.E.; Himawan, C.; Witkamp, G.-J. Inline determination of supersaturation and metastable zone width of MgSO4. $12 \mathrm{H} 2 \mathrm{O}$ with conductivity and refractive index measurement techniques. J. Cryst. Growth 2005, 275, e1757-e1762. [CrossRef]

5. Wang, S.; Feng, M.; Du, H.; Weigand, J.J.; Zhang, Y.; Wang, X. Determination of metastable zone width, induction time and primary nucleation kinetics for cooling crystallization of sodium orthovanadate from NaOH solution. J. Cryst. Growth $2020,125721$. [CrossRef]

6. Akal, M.M.; Zakaria, M.; Ebrahim, A.; Nassar, M.M. Secondary nucleation rate of sodium chloride under different stirring conditions. J. Cryst. Growth 1986, 78, 528-532. [CrossRef]

7. Anuar, N.; Daud, W.R.W.; Roberts, K.J.; Kamarudin, S.K.; Tasirin, S.M. An examination of the solution chemistry, nucleation kinetics, crystal morphology, and polymorphic behavior of aqueous phase batch crystallized L-isoleucine at the $250 \mathrm{~mL}$ scale size. Cryst. Growth Des. 2009, 9, 2853-2862. [CrossRef]

8. Kubota, N. A unified interpretation of metastable zone widths and induction times measured for seeded solutions. J. Cryst. Growth 2010, 312, 548-554. [CrossRef]

9. Yu, J.; Li, A.; Chen, X.; Chen, Y.; Xie, J.; Wu, J.; Ying, H. Experimental Determination of Metastable Zone Width, Induction Period, and Primary Nucleation Kinetics of Cytidine 5'-Monophosphate Disodium Salt in an Ethanol-Aqueous Mixture. J. Chem. Eng. Data 2013, 58, 1244-1248. [CrossRef]

10. Kongsamai, P.; Wantha, L.; Flood, A.E.; Tangsathitkulchai, C. In-situ measurement of the primary nucleation rate of the metastable polymorph B of L-histidine in antisolvent crystallization. J. Cryst. Growth 2019, 525, 125209. [CrossRef] 
11. Ryu, S.Y.; Oh, I.H.; Cho, S.J.; Kim, S.; Song, H.K. Enhancing Protein Crystallization under a Magnetic Field. Crystals 2020, 10 , 821. [CrossRef]

12. Kim, H.N.; Suslick, K.S. The effects of ultrasound on crystals: Sonocrystallization and sonofragmentation. Crystals 2018, 8, 280. [CrossRef]

13. Hammadi, Z.; Veesler, S. New approaches on crystallization under electric fields. Prog. Biophys. Mol. Biol. 2009, 101, 38-44. [CrossRef]

14. Nanev, C.N. Recent insights into the crystallization process; Protein crystal nucleation and growth peculiarities; Processes in the Presence of Electric Fields. Crystals 2017, 7, 310. [CrossRef]

15. Nanev, C.N.; Penkova, A. Nucleation of lysozyme crystals under external electric and ultrasonic fields. J. Cryst. Growth 2001, 232, 285-293. [CrossRef]

16. Amaro-Gahete, J.; Klee, R.; Esquivel, D.; Ruiz, J.R.; Jimenez-Sanchidrian, C.; Romero-Salguero, F.J. Fast ultrasound-assisted synthesis of highly crystalline MIL-88A particles and their application as ethylene adsorbents. Ultrason. Sonochem. 2019, 50, 59-66. [CrossRef]

17. Pan, W.; Xu, H.; Zhang, R.; Xu, J.; Tsukamoto, K.; Han, J.; Li, A. The influence of low frequency of external electric field on nucleation enhancement of hen egg-white lysozyme (HEWL). J. Cryst. Growth 2015, 428, 35-39. [CrossRef]

18. Koizumi, H.; Fujiwara, K.; Uda, S. Control of nucleation rate for tetragonal hen-egg white lysozyme crystals by application of an electric field with variable frequencies. Cryst. Growth Des. 2009, 9, 2420-2424. [CrossRef]

19. Dhanasekaran, R.; Ramasamy, P. Two-dimensional nucleation in the presence of an electric field. J. Cryst. Growth 1986, 79, 993-996. [CrossRef]

20. Hong, B.K.; Jo, W.H.; Hwang, I.S. The effect of electric field on the crystallization of polyamide- 6,6 by rheological measurement. Polymer 1996, 37, 4183-4185. [CrossRef]

21. Jung, D.H.; Yang, J.H.; Jhon, M.S. The effect of an external electric field on the structure of liquid water using molecular dynamics simulations. Chem. Phys. 1999, 244, 331-337. [CrossRef]

22. Koizumi, H.; Tomita, Y.; Uda, S.; Fujiwara, K.; Nozawa, J. Nucleation rate enhancement of porcine insulin by application of an external AC electric field. J. Cryst. Growth 2012, 352, 155-157. [CrossRef]

23. Tomita, Y.; Koizumi, H.; Uda, S.; Fujiwara, K.; Nozawa, J. Control of Gibbs free energy relationship between hen egg white lysozyme polymorphs under application of an external alternating current electric field. J. Appl. Crystallogr. 2012, 45, 207-212. [CrossRef]

24. Anuar, N.; Wan Mohamed Daid, W.N.A.; Khalid, S.A.; Syed Draman, S.F.; Sheikh Abdullah, S.R. Prediction of Interaction of Citric Acid Modified Cellulose with Water Region Using Molecular Modelling Technique. Key Eng. Mater. 2019, 797, 118-126. [CrossRef]

25. Rosbottom, I.; Roberts, K.; Docherty, R. The solid state, surface and morphological properties of p-aminobenzoic acid in terms of the strength and directionality of its intermolecular synthons. CrystEngComm 2015, 17, 5768-5788. [CrossRef]

26. Rosbottom, I.; Toroz, D.; Hammond, R.B.; Roberts, K.J. Conformational and structural stability of the single molecule and hydrogen bonded clusters of para aminobenzoic acid in the gas and solution phases. CrystEngComm 2018, 20, 7543-7555. [CrossRef]

27. Yusop, S.N.a.; Anuar, N.; Md Azmi, N.S.; Abu Bakar, N.H. Molecular dynamic investigation on the dissolution behaviour of carbamazepine form III in ethanol solution. Key Eng. Mater. 2019, 797, 149-157. [CrossRef]

28. Anuar, N.; Pauzi, N.; Ain Yusop, S.; Azmi, N.; Rahim, S.; Othman, M. Prediction of carbamazepine-succinic acid co-crystal dissolution in ethanolic solution using a computational molecular dynamic simulation technique. Int. J. Eng. Technol. (UAE) 2018, 7, 122-128.

29. Anwar, J.; Boateng, P.K. Computer simulation of crystallization from solution. J. Am. Chem. Soc. 1998, 120, 9600-9604. [CrossRef]

30. Othman, M.F.; Anuar, N.; Yusop, S.N.a.; Md Azmi, N.S.; Abd Samad, N.A. Morphology prediction and dissolution behavior of $\alpha$-succinic acid in ethanol solution using molecular dynamic simulation. Key Eng. Mater. 2019, 797, 139-148. [CrossRef]

31. Shim, H.-M.; Kim, J.-K.; Kim, H.-S.; Koo, K.-K. Molecular dynamics simulation on nucleation of ammonium perchlorate from an aqueous solution. Cryst. Growth Des. 2014, 14, 5897-5903. [CrossRef]

32. Gavezzotti, A. Molecular aggregation of acetic acid in a carbon tetrachloride solution: A molecular dynamics study with a view to crystal nucleation. Chem. A Eur. J. 1999, 5, 567-576. [CrossRef]

33. Cheong, D.W.; Boon, Y.D. Comparative study of force fields for molecular dynamics simulations of $\alpha$-glycine crystal growth from solution. Cryst. Growth Des. 2010, 10, 5146-5158. [CrossRef]

34. Yuhara, D.; Barnes, B.C.; Suh, D.; Knott, B.C.; Beckham, G.T.; Yasuoka, K.; Wu, D.T.; Sum, A.K. Nucleation rate analysis of methane hydrate from molecular dynamics simulations. Faraday Discuss. 2015, 179, 463-474. [CrossRef] [PubMed]

35. Yasuoka, K.; Matsumoto, M. Molecular dynamics of homogeneous nucleation in the vapor phase. I. Lennard-Jones fluid. J. Chem. Phys. 1998, 109, 8451-8462. [CrossRef]

36. Florence, A.T.; Attwood, D. Physicochemical Principles of Pharmacy: In Manufacture, Formulation and Clinical Use; Pharmaceutical Press: London, UK, 2015.

37. Torii, K.; Iitaka, Y. The crystal structure of L-isoleucine. Acta Crystallogr. Sect. B: Struct. Crystallogr. Cryst. Chem. 1971, 27, 2237-2246. [CrossRef] 
38. Curland, S.; Meirzadeh, E.; Diskin-Posner, Y. Crystal structure of a new polymorph of (2S, 3S)-2-amino-3-methylpentanoic acid. Acta Crystallogr. Sect. E: Crystallogr. Commun. 2018, 74, 776-779. [CrossRef] [PubMed]

39. Azmi, N.S.M.; Anuar, N.; Roberts, K.J.; Bakar, N.F.A.; Aripin, N.F.K. Molecular aggregation of L-isoleucine in aqueous solution and its impact on the determination of solubility and nucleation kinetics. J. Cryst. Growth 2019, 519, 91-99. [CrossRef]

40. Sun, H.; Jin, Z.; Yang, C.; Akkermans, R.L.; Robertson, S.H.; Spenley, N.A.; Miller, S.; Todd, S.M. COMPASS II: Extended coverage for polymer and drug-like molecule databases. J. Mol. Modeling 2016, 22, 47. [CrossRef]

41. Chami Khazraji, A.; Robert, S. Interaction effects between cellulose and water in nanocrystalline and amorphous regions: A novel approach using molecular modeling. J. Nanomater. 2013, 2013. [CrossRef]

42. Liu, H.; Li, Y.; Krause, W.E.; Rojas, O.J.; Pasquinelli, M.A. The soft-confined method for creating molecular models of amorphous polymer surfaces. J. Phys. Chem. B 2012, 116, 1570-1578. [CrossRef]

43. Yürüdü, C.; Jones, M.J.; Ulrich, J. Modeling of diffusion for crystal growth. Soft Mater. 2012, 10, 257-284. [CrossRef]

44. Zeng, J.; Wang, A.; Gong, X.; Chen, J.; Chen, S.; Xue, F. Molecular dynamics simulation of diffusion of vitamin c in water solution. Chin. J. Chem. 2012, 30, 115-120. [CrossRef]

45. Mudalip, S.A.; Bakar, M.A.; Jamal, P.; Adam, F.; Alam, Z. Molecular recognition and solubility of mefenamic acid in water. Asian J. Chem. 2016, 28, 853. [CrossRef]

46. Rabesiaka, M.; Porte, C.; Bonnin-Paris, J.; Havet, J.-L. An automatic method for the determination of saturation curve and metastable zone width of lysine monohydrochloride. J. Cryst. Growth 2011, 332, 75-80. [CrossRef]

47. Smith, L.; Duncan, A.; Thomson, G.; Roberts, K.; Machin, D.; McLeod, G. Crystallisation of sodium dodecyl sulphate from aqueous solution: Phase identification, crystal morphology, surface chemistry and kinetic interface roughening. J. Cryst. Growth 2004, 263, 480-490. [CrossRef]

48. Berlin, E.; Pallansch, M. Densities of several proteins and L-amino acids in the dry state. J. Phys. Chem. 1968, 72, 1887-1889. [CrossRef]

49. Chianese, A. Characterization of crystal size distribution. Ind. Cryst. Process Monit. Control 2012.

50. El-Shall, H.; Jeon, J.h.; Abdel-Aal, E.; Khan, S.; Gower, L.; Rabinovich, Y. A study of primary nucleation of calcium oxalate monohydrate: I-Effect of supersaturation. Cryst. Res. Technol. J. Exp. Ind. Crystallogr. 2004, 39, 214-221. [CrossRef]

51. Mullin, J.W. Crystallization; Elsevier: Oxford, UK, 2001.

52. Ghader, S.; Manteghian, M.; Kokabi, M.; Mamoory, R.S. Induction time of reaction crystallization of silver nanoparticles. Chem. Eng. Technol. Ind. Chem. Plant Equip. Process Eng. Biotechnol. 2007, 30, 1129-1133. [CrossRef]

53. Zhan, L.; Zhang, Y.; Zheng, S.; Zhang, Y.; Fan, B.; Li, P.; Zhang, Y. Crystallization kinetics of ammonium polyvanadate. J. Cryst. Growth 2019, 526, 125218. [CrossRef]

54. Fan, S.; Gu, X.; Zhou, X.; Duan, X.; Li, H. Determination of Nucleation Kinetics from the Induction Time of 1, 1-Diamino-2, 2-Dinitroethylene (FOX-7) in DMSO/Water. Energetic Mater. Front. 2021, 2, 62-68. [CrossRef]

55. Saban, K.; Thomas, J.; Varughese, P.; Varghese, G. Thermodynamics of crystal nucleation in an external electric field. Cryst. Res. Technol. J. Exp. Ind. Crystallogr. 2002, 37, 1188-1199. [CrossRef]

56. Abdel-Aal, E.; El-Shazly, A.; El-Shahat, M. Crystal nucleation of nano crystallite strontium malonate without and with additives. Cryst. Growth Des. 2013, 13, 4395-4401. [CrossRef]

57. Yoshioka, M.; Hancock, B.C.; Zografi, G. Crystallization of indomethacin from the amorphous state below and above its glass transition temperature. J. Pharm. Sci. 1994, 83, 1700-1705. [CrossRef] [PubMed]

58. Koryta, J.; Dvořák, J.; Kavan, L. Principles of Electrochemistry; John Wiley \& Sons Inc: Chichester, UK, 1993. 